E. I. du Pont de Nemours É Company

\section{incomonars}

SAVANNAH RIVER LABORATORY AIKEN. SOUTH CAROLINA-29808-0001

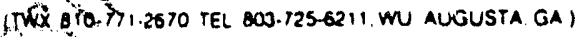
$+4$

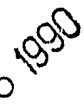

\section{DPST-86-390-.T.}

DE91 004275

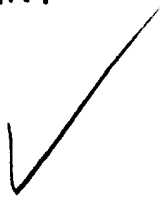

\section{IP-10374}

Radiolysis efrects, benzena, in-tank proceseing, salt docontamination, totrapheny lborate

CC: I. Hibbard, SRP

I. M. Papouchado

J. E. Haywood

D. C. Nichols

D. I. McIntosh, SRL, 773-A

J. R. Knight, 773-A

N. E. Bibler, 773-A

M. A. Ebra, 773-A

D. D. Walker, 773-A

SRL Records (4), 773-A

January 15,1987

J. T. GRANAGHAN, PLANT MANAGER

SAVANNAH RIVER PLANT

ATTENTION: W. B. BOORE (4)

SUPERINTENDENT, WASTE MANAGEMENT TECHNOLOGY

\title{
TECHNICAI REPORT - BENZENE DISTRIBUTION IN PRODUCT STREAMS FROM IN-TANK PROCESSING
}

Attached is DPST-86-390, "Benzene Distribution in Product Streams from In-Tank Processing." This document summarizes the current information on the radiolytic decomposition of potassium tetraphenylborate and benzene production from in-tank processing. It includes information obtained from the full scale in-tank demonstration, subcontract work by the University of Florida, and small scale experiments at the Savannah River Laboratory. The amount of benzene which will be produced from in-tank processing and the composition of the slurry after storage can be estimated from the imformation provided. Areas in which further work is planned are also discussed.

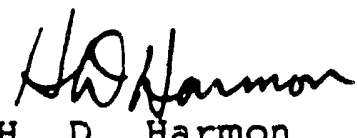

H. D. Harmon

Research Manager

Interim Waste Technology Division 
TECHNICAL DIVISION

SAVANNAH RIVER LABORATORY
Radiolysis effects,

benzene, in-tank

processing, salt

decontamination,

tetrapheny lborate

DPST-86-390
CC: H. D. Harmon, $773-\mathrm{A}$
J. R. Knight, $773-\mathrm{A}$
M. D. Boersma, $676-\mathrm{T}$
N. E. Bibler, $773-\mathrm{A}$
C. T. Randali, $704-\mathrm{T}$
J. P. Ryan, $773-41 \mathrm{~A}$
I. F. Landon, $704-\mathrm{T}$
J. R. Fowler, $704-\mathrm{T}$
J. C. Marek, $704-\mathrm{T}$
January 15, 1987

J. R. Knight, 773-A

M. D. Boersma, 676-T

N. E. Bibler, 773-A

C. T. Randal1, 704-T

J. P. Ryan, 773-41A

L. F. Landon, 704-T

J. R. Fowler, 704-T

J. C. Marek, 704-T

January 15, 1987

TO: M. A. EBRA

EROM: D. D. WALKER GEqL

Benzene Distribution in Product Streams From In-Tank Processing

Summary

Benzene is the major product of radiolytic decomposition of tetraphenylborate salts during in-tank salt decontamination. Its production rate has been measured at the Savannah River Laboratory (SRL) and at the University of Florida under various conditions of importance to the in-tank process. Recent work has been concerned with the extent of decomposition for long storage periocis, and the composition of the product streams from the process. The major results from this work are:

- The stored potassium tetraphenylborate precipitate will decompose at a rate of $7.3 \pm 1.1$ \% per year.

- The major products of the decomposition are benzene, phenol, biphenyl, and phenylboric acid.

- Decomposition is directly proportional to the total dose and is unaffected by dose rate.

- The decomposition produces acidic compound which will. cause a decrease in the $\mathrm{pH}$ of the storage tank.

The final report on the work done at the University of Florida is attached (see Appendix A). Although the subcontract with the University of F'lorida has ended, further work on the effects of radiation on tetraphenylborate solutions and slurries is still being pursued at SRL. 
Introduction

The in-tank process for decontaminating the Savannah River Plant's high activity soluble waste will use sodium tetraphenylborate to precipitate cesium-137 (Ref. 1). The precipitate slurry from this process will be stored for two years in the tank farm before it is sent to the Defense Waste Processing Facility (DWPF) where it will be incorporated in borosilicate glass. During the precipitation process and storage period, the precipitate slurry will be subjected to intense beta and gamma irradiation. As a result, some of the precipitate will decompose to smaller organic molecules such as benzene, phenol, and biphenyl. This decomposition has been studied at the Savannah River Laboratory and, by subcontract, at the University of Florida. Results of this work have been published previously (Ref. 2-6). The major product of the decomposition is benzene and it has been the cause of much concern because of its flammability and carcinogenicity. The amount of benzene produced is very important to safety and regulatory requirements in the. Tank Farm where the precipitate is stored. Its presence in the product streams (decontaminated salt solution, recycled wash water, and concentrated slurry) is also important to the design of other facilities. In addition, the extent of the decomposition is important to the acid hydrolysis process for converting the precipitate into feed for the DWPE glass melter.

The results from the full scale in-tank demonstration (Ref. 7) and later small scale tests (Ref. 2-3), have shown that the decomposition products from radiolyis are of two kinds: "free" and "trapped". The free products are believed to be produced at the surface of the KTPB particles and are free to dissolve in the solution or evaporate into the air. The "trapped" products are formed on the inside of the KTPB particles and are held in the crystal lattice. The "trapped" products are released if the crystal is dissolved, such as occurs in the washing step of the in-tank process when the excess NaTPB is recovered in the wash water.

A calculation of the radiation dose expected for stored slurry is given in Appendix B. Normally, doses are expressed in rads. However, throughout this report the radiation doses will be given in terms of equivalent years of tank farm storage so that an easy comparison with planned tank farm operations can be made. During one year of storage, a slurry with the average level of Cs-137 ( 36 $\mathrm{Ci} / g a l)$ will receive a dose of $1.45 \times 10^{8}$ rads. Currently, it is planned that the KTPB precipitate will be stored for approximately two years before it is sent to the DWPE.

\section{Badiolytic Decomposition Rate for KTPB and Effect of Dose Rate}

Previously, it was estimated that $12 \pm 5 \%$ of the KTPB decomposed from a dose equivalent to two years of storage (Ref. 3). Further experiments have been completed at SRL and the University of Florida which have more accurately measured the rate of decomposition and which have given the overall product distribution. Based on the most recent data, $15 \pm 28$ of the stored KTPB is expected to decompose during two years of storage. 
The decrease in KTPB after exposure to radiation is shown in Figure 1. This was measured at SRI on a 10 wt 8 KTPB siurry with a low dissolved salt concentration, simulating the washed precipitate. The nominal composition of the slurry is listed in Table I. The loss of KTPB is approximately linear with dose, similar to the behavior observed at the University of Florida (see Appendix A, Figure 7). The G-values for the loss of KTPB are given in Table II. There does not appear to be any significant trend due to dose rate. The average G-value $(0.13 \pm .02$ molecules/100eV) corresponds to $7.3 \pm 1.18$ decomposition of the KTPB per year of tank farm storage.

A lower limit on the rate of KTPB decomposition can be calculated from measurements of cesium release from the precipitate made in the full scale in-tank demonstration. That precipitate has been stored in Tank 48 for over three years, and, as it decomposes, the cesium-137 is released to the supernate. As long as there is excess sodium tetraphenylborate, the free cesium and potassium will be reprecipitated. When the excess sodium tetraphenylborate is all consumed, the cesilim level in the supernate should increase at a raice related to the overall decomposition rate. However, since some of the cesium may be trapped within crystals, the rate of decomposition measured in this way should be less than the rate measured in the small scale experiments. The cesium levels measured in Tank 4.9 are given in Table III. The rate of accumulation of cesium has been constant over the time covered by the last four samples. This implies that the excess NaTPB has been consumed and, also, that the KTPB is decomposing at a constant rate. The rate of increase in cesium corresponds to a decomposition rate of 0.88 per year (see Appendix D). When corrected for the low cesium concentration in Tank 48, the decomposition rate would be $2.0 \%$ per year (for "average" slurry). This is only $27 \%$ of the decomposition predicted by the small scale experiments and is consistent based on the argument given above.

\section{Decomposition Products}

The major products from radiolytic decomposition of KTPI3 are benzene, phenol, biphenyl, and phenylboric acid (phenylboronic acid, $\mathrm{C}_{6} \mathrm{H}_{5} \mathrm{~B}(\mathrm{OH})_{2}$ ). The amounts of these compounds found at different radiation doses are shown in Figures 2 to 5 . These results, obtained at SRI, reflect the total production of the compounds and do not distinguish "free" and "trapped" species.

The total amourt of benzene produced in the SRL experiments is shown in Figure 2. From this data, the production of benzene appears to bs linear with total dose and $G_{\text {benzene }}=0.38$. These results contrast with the non-linear behavior observed by the University of Florida (Appendix A, Figure 5) and will be discussed further below.

Phenol is the second most abundant product from the decompssition of tetraphenylborate. At low doses, its production is linear with radiation dose (see $F$ igure 3 ). At a dose equivalent to two years storage, the phenol yield is approximated by $G=0.16$. However, 
after two years, the level of phenol stops increasing. It may be that the phenol concentration has reached a steady state level, where its rate of formation is equal to its rate of reaction to form other products. In earlier work, the University of Elorida noted the production of phenol when homogeneous solutions of NaTPB were irradiated (Ref. 2), but due to experimental complications, they were not able to measure phenol in their latest report

(Appendix A).

The formation of biphenyl is similar to that of phenol (see pigure 4). Initially, it is almost linear with radiation dose, but then rapidly slows after about 1.5 years. At two years, the product yield is given by $G=0.066$. Similar behavior was observed by the University of Florida (see Appendix A, Eigure 6). The University of Florida experiments also distinguished between "free" and "trapped" biphenyl. The amount of "free" biphenyl was much lower than "trapped," and decreased slightly with increasing dose (see Appendix A, Figure 4). When the two contributions are added together, the behavior is very similar to that found at SRI, although about $35 \%$ less biphenyl was found (two year product yield of $G=0.044$ ).

The major boron-containing product observed from the decomposition was phenylboric acid. Changes in its concentration with increasing radiation dose are shown in Figure 5. Its behavior is similar to phenol and biphenyl, accumulating rapidly at first, then becoming almost constant after a dose equivalent to two years of storage. The product yield at two years is given by $G=0.090$. This compound was not measured in the experiments at the University of Florida.

Nitrobenzene was identified and quantified in the experiments at the University of Florida. All of the nitrobenzene was found in the aqueous phase ("free"). This is expected since the nitrate and nitrite ions in solution are required for its formation. The yield of this product was much lower than for the compounds mentioned above, although the general behavior was similar. The nitrobenzene increased until a radiation dose equivalent to two years of storage was reached, whereupon it began to decline slowly (see Appendix A, Figure 3). The yield of nitrobenzene was about 1 of of that observed for phenylboric acid, with a product yield at two years of $G=$ 0.0013 . No attempt was made to detect nitrobenzene in the SRI work.

The three isomeric terphenyls were also detected in the University of Florida work but they were not quantified (see Appendix A). The yields were very low with estimated G-values less than 0.001 .

compesition of Precipitate slurry after Two Years of sterage

The expected composition of a slurry stored for two years may be calculated from the SRI data. A material balance of the products after a two year equivalent radiation dose is shown in Table IV. The accuracy of the balance is shown by summing the G-values: 


$$
\begin{aligned}
4 G_{(-K T P B} & =G_{\text {jenzene }}+G_{\text {phenol }}+2 G_{\text {biphenyl }}+G_{\text {PBA }} \\
4(0.16) & =(0.29)+(0.16)+2(0.066)+(0.09) \\
0.64 & \approx 0.67
\end{aligned}
$$

The KTPB and benzene G-values are calculated from the two year dose data only and are slightly different than the average data for all experiments.

The corresponding change in the slurry composition for $15 \%$ decomposition in two years is shown in Table $V$. The equivalent balanced chemical reaction is shown below:

$$
\begin{aligned}
& \mathrm{KB}\left(\mathrm{C}_{6} \mathrm{H}_{5}\right)_{4}+\mathrm{H}_{2} \mathrm{O}+\mathrm{OH}^{-} \longrightarrow \mathrm{C}_{6} \mathrm{H}_{6}+\mathrm{C}_{6} \mathrm{H}_{5} \mathrm{O}^{-}+\left(\mathrm{C}_{6} \mathrm{H}_{5}\right)_{2} \\
& 1.00 \text { mole } 1.94 \quad 1.47 \\
& \text { KTPB }
\end{aligned}
$$

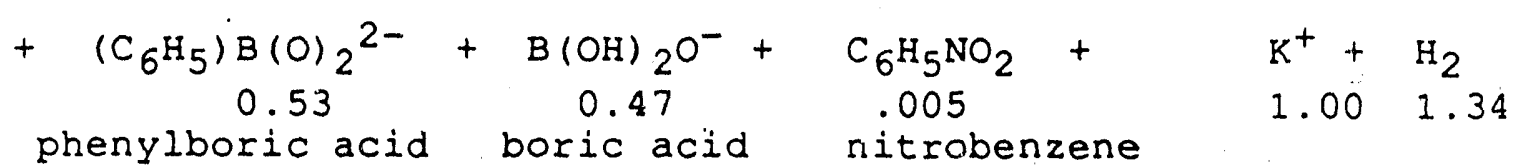

Several assumptions have been used to obtain the reaction equation above. First, the products are written as their ionized forms at $\mathrm{pH}=11$ (Ref. 11). The $\mathrm{pH}$ changes in the system are described below, but the net effect is that radiolysis consumes hydroxide. Boric acid was assumed to be the final product for all of the boron not accounted for by the phenyiboric acid and undecomposed KTPB.

The amount of hydrogen gas shown is simply that required to balance the equation. Experiments at the University of Florida (Ref. 2) have indicated that more hydrogen than this is actually formed. of the decomposition products identified, four (phenol, biphenyl, terphenyl, and nitrobenzene) are oxidized relative to the tetraphenylborate ion. The latter two occur in such small amounts that they do not figure significantly in the balanced reaction. It is possible that hydrogen peroxide, an oxidation product from the radiolysis of water, may also be present (it was not analyzed for). There are several reduction reactions occurring in the system. In addition to the formation of hydrogen gas, it is known that nitrate ion is reduced to nitrite, and it is likely that dissolved oxygen gas is reduced to water, hydrogen peroxide, or phenol.

The composition given in Table $\mathrm{V}$ assumes that the volatile compounds are not lost in the storage tank ventilation system. The benzene shown is the sum of all that is formed, both "free" and "trapped," and the actual amount which accumulates in the storage tank will depend on how much evaporates over two years.

Significant amounts of biphenyl, nitrobenzene, and phenol could also be lost by vaporization (Ref. 12). For phenol, this will depend greatly on the $\mathrm{pH}$ of the slurry, since at $\mathrm{pH}$ 's above its $\mathrm{pK}_{\mathrm{a}}$ it will be ionized and will not be volatile. 
It should be noted that the loss of KTPB is linear with dose for at least 5 years of storage (Figure 1), but the formation of the major decomposition products is only appioximately linear for two years, and is quite non-linear after two years. This implies that other products, as yet unidentified, are being made after two years.

\section{RH Changes During Radiolysis}

Radiolysis of KTPB slurries produces acidic decomposition products which neutralize the sodium hydroxide and cause a decrease in $\mathrm{pH}$. In tests where carbon dioxide adsorption from the atmosphere was negligible, approximately 0.01 mole of caustic was consumed per $1.2 \times 10^{6}$ rads of gamma radiation duse (this corresponds to one month of storage under planned tank farm operations for a slurry of average composition). The changes in $\mathrm{pH}$ are shown in Figure 6 . one curve is for a 10 wt 8 KTPB slurry in dilute salt solution containing approximately 0.075 molar $\mathrm{NaOH}$ initially. The second curve is for the dilute salt solution only. The $\mathrm{pH}$ of the salt solution changed very little during the irradiation, indicating no significant adsorption of carbon dioxide occurred. However, a large decrease occurred in the pH of the KTPB slurry. The pH of 9.5 at the end of the experiment is consistent with the formation of a solution buffered by phenol, phenylboric acid, and boric acid. In a separate experiment in which air (containing carbon dioxide) was circulated over the slurry, the $\mathrm{pH}$ dropped even faster than in the experiment shown in Eigure 6 .

The rate of hydroxide depletion can be calculated from the slope of the early portion of the curve for the KTPB slurry. This

corresponds to approximately $0.01 \mathrm{molar} / \mathrm{month}$. This is significantly faster than was calculated based on the decomposition equations given above. For $15 \%$ decomposition in two years, the rate of hydroxide depletion should be about 0.0025 molar/month due to the formation of acidic decomposition products. The reason for the much higher observed rate is not known. There may be a slight contribution from carbon dioxide adsorption (see Figure 6), but it does not account for all of the difference.

Previously, it had been reported that radiolysis of KTPB slurries caused the $\mathrm{pH}$ of the solution to increase (Ref. 2). In those experiments, the original slurry was in water with no dissolved salts or sodium hydroxide. The inital $\mathrm{pH}$ was near neutral. In that case, the production of phenol, phenylboric acid, and boric acid drove the pH up, producing the same buffer solution, but approaching the equilibrium from the acidic side.

\section{Estimates of Benzane Production}

Table VI lists the G-values found for benzene yields from different experimental sources. A considerable range has been observed, depending on the slurry composition and total radiation dose. However, the most recent G-values, measured at high doses and with dissolved salts present, only vary between 0.16 and 0.38 . This may be compared to the maximum possible benzene production rate. The rate of loss of KTPB sets an upper limit on the amount of benzene 
that can be formed. If $G_{(-K T P B}$ is 0.13 (Table II), then Gbenzene must be $\leq 0.52$ (total of trapped and free benzene).

The variations in $G_{\text {benzene within the range } 0.38-0.16 \text { agree }}$ qualitatively with the assumption that some of the benzene is "trapped" and some is "free." The largest value, $G=0.38$, was obtained in the SRL experiment that measured the combined "trapped" and "free" benzene. The low G-value of 0.17 from the Tank 48 exhaust emissions is a measure of "free" benzene only. The University of florida results for "trapped" benzene, which vary between 0.31-0.16 depending on total dose, are compatible with the other data within the experimental error. The earlier University of Florida results with G-values of $0.7-7.5$ exceed the upper limit set by the loss of KTPB. These large rates were all measured at very low radiation doses and are not applicable to predictions of benzene production for long storage times.

Based on the most recent data from all three sources, the best G-values for predicting benzene production for long storage times are:

$\mathrm{G}_{\text {benzene }}$ (total) $=0.4 \pm .1$
$\mathrm{G}_{\text {benzene }}$ (free) $=0.2 \pm .1$
$\mathrm{G}_{\text {benzene }}$ (trapped) $=0.2 \pm .1$

There appears to be a significant effect on "free" benzene production due to the presence of dissolved salts. Compare the following results: $G=0.71$ with no dissolved salts present ( $U$. of F., Ref. 2), $G=0.17$ for low levels of dissolved salt (Tank 48), and $G=0$ with high dissolved salt levels (U. of $F .$, Ref. 3).

Although a strict comparison cannot be made from this data, it does suggest that higher salt concentrations reduce the amount of "free" benzene and this aspect should be studied in more detail. This is not a completely surprising trend, since nitrate ion, the major soluble anion, acts as a radical scavenger in aqueous systems (Ref. 13). The high "free" benzene yields observed with smali doses ( $G=$ $0.7)$ may be applicable to the precipitation and filtration steps of the in-tank process. The current plans call for three consecutive batch precipitations prior to the washing step and the time required is 45 days. The experimental results imply that a higher benzene production rate should be observed with the fresh slurry during the initial exposure to radiation (ignoring any effect by dissolved salts). This was not corroborated by the full-scale in-tank demonstration. Prior to the washing step, less than 4 ppb benzene were found in the Tank 48 ventilation exhaust. Even with the low radioactivity level in that precipitate, benzene concentrations in the ppm range should have been observed if the $G$-value was 0.7 . However, if dissolved salts greatly reduce this G-value, this apparent contradiction may not actually exist.

The amount of "trapped" benzene which will be released during slurry washing can be estimated from the data given in Reference 3 (see Figure 1 in that report), or from the data listed in Table VI $\left(G_{\text {initial }}=6.7, G_{\text {half-year }}=1.1\right.$, and $\left.G_{2 \text {-year }}=0.6\right)$. The production 
yield varies considerably with dose at doses equivalent to half a year of storage or less. An average over the first 45 days (equivalent storage) cannot be determined from the data at hand, but must lie between 1.6 anci 6.7 . The results from the in-tank demonstration suggest a G-value of 3.4 , but this is a highly speculative number since only a very approximate estimate of the total benzene release can be made. In addition, the low dose received by this material may produce an overestimate of the G-value when compared to the larger doses the normal operations will involve.

\section{Eurther Work}

Several areas of interest still need further research. Some of these items are listed below.

- Radiolysis effects on nitrate and nitrite concentrations. A clear understanding of this process is needed to assure the storage tank is adequately protected against corrosion.

- Radiclysis of unwashed slurries for short storage times. The effect of high concentrations of nitrate and nitrite ions needs to be more closely examined since it may affect the amount of "free" benzene produced. This is most important in estimating the amount of benzene which will go to saltstone.

- Radiolysis of undissolved NaTPB. More data at short doses in the presence of high salt concentrations is needed to estimate "trapped" benzene. The results are applicable to benzene emissions during precipitate washing in Tank 48 .

- Effect of nitrate and nitrite ion on product distribution. Most of the data discussed above were obtained at low salt concentrations. If nitrite ion concentration is increased to prevent tank corrosion, it could affect the product distribution from radiolytic decomposition. This would be important to the acid hydrolysis process in the salt cell of the DWPF.

\section{Quality Assurance}

Quality assurance of the new data reported here is covered by DPSTQA-85-2-25, Quality Assurance Review: Decontamination of Soluble Defense Waste by In-Tank Precipitation Processing." The data are recorded in Laboratory Notebook DPSTN-4274 and DPSTN-4443.

\section{Experimental}

For the radiolytic decomposition studies, 0.2 to 0.3 gram of 10 wt \% KTPB slurry was sealed in a $9 \mathrm{ml}$ glass vial with aluminum lined septum cap. Care was taken to avoid contacting the aluminum with the caustic slurry. The vials were irradiated in a co-60 gamma 
source with a dose rate of $3 \times 10^{6}$ rads/h. Following irradiation, the samples were dissolved by injecting $1 \mathrm{ml}$ of propylene carbonate into the vial.. Portions were then diluted in acetonitrile and injected into a Varian HPLC. The decomposition products were separated by reverse phase liquid chromatography using a water/acetonitrile elution sytem. The large tetraphenylborate peak was separated from the other product peaks by ion pairing it with $0.005 \mathrm{M}$ tetrabutylammonium phosphate in the aqueous phase.

The 10 wt 8 precipitate slurry was prepared from reagent grade chemicals except for the sodium tetraphenylborate. The NaTPB was obtained from material left over from the 1983 full scale in-tank demonstration and is a mixture of products from Boulder Scientific, Raylo Chemicals, and AFF, Inc. A significant blank correction had to be made only for phenylboric acid.

For the pH studies, 12 to 15 grams of slurry were placed in a glass vial and capped. After irradiation, the samples were filtered in air and the $\mathrm{pH}$ of the filtrate measured immediately. It was not possible to obtain a steady $\mathrm{pH}$ reading in the presence of the KTPB precipitated, probably due to plugging of the electrode's ceramic junction.

\section{DISCLAIMER}

This report was prepared as an account of work sponsored by an agency of the United States Government. Neither the United States Grvernment nor any agency thereof, nor any of their employees, makes any warranty, express or implied, or assumes any legal liability or responsibility for the accuracy, completeness, or usefulness of any information, apparatus, product, or process disciosed, or represents that its use would not infringe privately owned rights. Reference herein to any specific commercial product, process, or service ty trade name, trademark, manufacturer, or otherwise does not necessarily constitute or imply its endorsement, recommendation, or favoring by the United States Government or any agency thereof. The views and opinions of authors eipressed herein do not necessarily state or reflect those of the I nited States Government or any agenry thereof. 


\section{References}

1. D. D. Walker and M. A. Schmitz, "Technical Data Summary: In-Tank Precipitation Processing of Soluble High-Level waste," DPSTD-84-103, May, 1984.

2. D. D. Walker, "Radiolysis of Tetraphenylborate: University of Florida Trip Report," DPST-84-827, October 18, 1984.

3. D. D. Walker, "Radiolysis of Tetraphenylborate: University of Florida Trip Report," DPST-85-468, April 17, 1985.

4. D. D. Walker and B. S. Johnston, "Radiolytically Induced Changes in the Concentrations of Nitrate and Nitrite Ions in Potassium Tetraphenylborate Slurries," DPST-86-716, October $14,1986$.

5. D. D. Walker, "Vapor Pressure of Benzene Over Irradiated Tetraphenylborate Slurries," DPST-86-646, fugust 18, 1986.

6. D. D. Walker, "Estimate of Radiolytically Produced Benzene in Decontaminated Salt Solution," DPST-86-722, October 15, 1986.

7. E. B. Snell and C. J. Heng, "Salt Decontamination Demonstration Test Results," DPSP 83-17-8, June 20, 1983.

8. Defense Waste Processing Facility Basic Data Report (Rev. 91), Appendix I, DPSP-80-1033, December, 1984.

9. D. D. Walker and B. A. Hamm, "Sample Analyses from the Full Scale In-Tank Demonstration of the Precipitation Process," DPST-83-695, July 21, 1983.

10. Persunal communication with D. T. Hobbs, results recorded in DPSTN -4379 .

11. The pKa's for the decomposition products are: phenol, 9.9; phenylboric acid, 8.7 and 8.9 ; boric acid, 9.1, 12.7, and 13.8. See the CRC Handbook of Chemistry and Physics, 61st Ed., 1981, R. C. Weast, Ed., CRC Press, Inc., Boca Raton, Fla.

12. The vapor pressures of the more volatile compounds are: benzene, $100 \mathrm{~mm}$ at $26^{\circ} \mathrm{C}$; nitrobenzene, $1 \mathrm{~mm}$ at $44^{\circ} \mathrm{C}$; phenol, $1 \mathrm{~mm}$ at $40^{\circ} \mathrm{C}$; biphenyl, $1 \mathrm{~mm}$ at $71^{\circ} \mathrm{C}$. See the CRC Handbook of Chemistry and Physics, 61st Ed., 1981, R. C. Weast, Ed., CRC Press, Inc., Boca Raton, Fla.

13. N. E. Bibler, J. Phys. Chem., 78, 211 (1974). 
TABLE I

Composition of 10 Weight of KTPB Slurry

\section{component}

$\begin{array}{ll}\text { Solids: } & \mathrm{KTPB} \\ \text { Solution: } & \mathrm{Na}^{+} \\ & \mathrm{NO}_{2}^{-} \\ & \mathrm{NO}_{3}^{-} \\ & \mathrm{OH}^{-}\end{array}$

\section{cencentration}

$9 \pm 1$ wt 8

0.18 molar

0.026 molar

0.084 molar

0.072 molar

TABLE II

Rate of KTPB Decomposition

Dese Rate (rads/hr) ${ }^{1}$

$G(-K T P B)$ (molecules/100 eV)
$3.4 \times 10^{6}(\mathrm{SRL})$
$3.0 \times 10^{5}$ (U of $\left.E\right)^{2}$
$1.0 \times 10^{5}(U \text { of } F)^{2}$
$0.12 \pm .02$
0.12
0.15

1 The dose rate expected in the storage tank for average 2 composition slurry is $1.7 \times 10^{4} \mathrm{rads} / \mathrm{hr}$.

See Appendix B for University of Florida data. 


$\begin{array}{cc}\text { Date of sample } & \begin{array}{c}C s-137 \\ \text { (uCi/mL }\end{array} \\ 4 / 20 / 83 & 0.2^{1} \\ 11 / 11 / 84 & 12 . \\ 12 / 12 / 84 & 14 . \\ 1 / 1 / 86 & 22.2 \\ 5 / 4 / 86 & 25.2\end{array}$

1 Reference 9.

2 Reference 10.

TABLE IV

Material Balance for Two Year Equivalent Radiation Dose

compenent

benzene

phenol

biphenyl

phenylboric acid

KTPB (lost)
Yield

sumeles $/ \mathrm{mI}$ )

87. \pm 18 .

47. \pm 4 .

20. \pm 2 .

27. \pm 2 .

47. \pm 2 .
G-value lmolecules $/ 100 \mathrm{eVL}$

$$
0.29
$$

0.16

0.066

0.090

0.16 


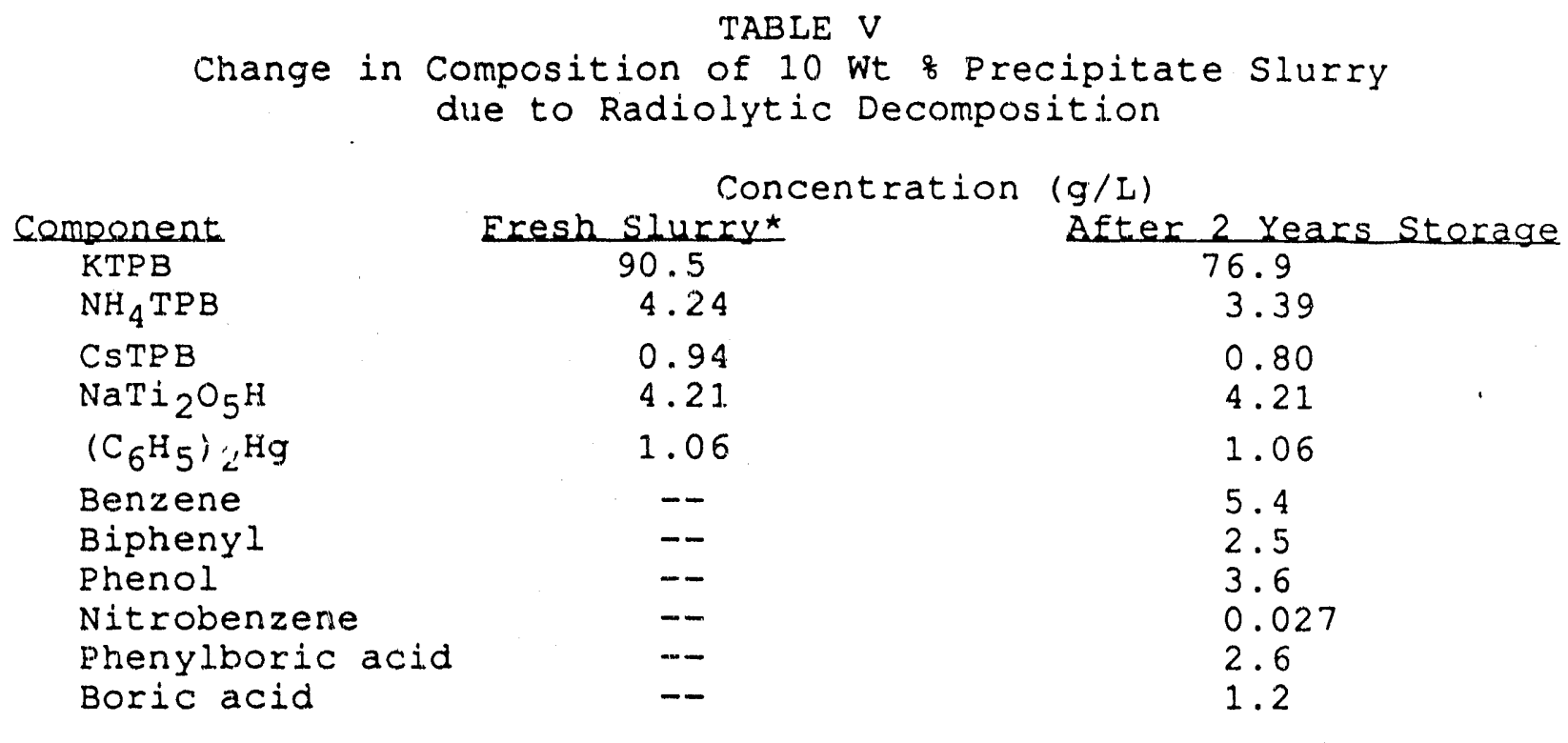

ऋ See Reference 8. 
TABLE VI

Summary of G-Values for Benzene Production

\begin{tabular}{|c|c|c|c|}
\hline Source & Erodust & G & comments \\
\hline SRI 1 & Total & 0.38 & $\begin{array}{l}\text { washed precipitate, } 10 \text { wt } 8 \\
\text { linear with dose to } 5 \text { yr }\end{array}$ \\
\hline Tank $48^{2}$ & Eree & 0.17 & $\begin{array}{l}\text { low dose rate, washed precipitate } \\
\text { approx. } 0.8 \mathrm{yr} \text { dose equivalent }\end{array}$ \\
\hline $\mathrm{UE}^{3}$ & $\begin{array}{l}\text { Trapped } \\
\text { Trapped }\end{array}$ & $\begin{array}{l}0.31 \\
0.16\end{array}$ & $\begin{array}{l}\text { washed precipitate, } 6 \text { wt } 8 \\
\text { initial production rate } \\
\text { after } 2-y r \text { dose }\end{array}$ \\
\hline$U F^{4}$ & $\begin{array}{l}\text { Eree } \\
\text { Trapped }\end{array}$ & $\begin{array}{l}0.71 \\
7.07\end{array}$ & $\begin{array}{l}\text { low total dose, no dissolved salts } \\
10 \text { wt \& KTPB }\end{array}$ \\
\hline & $\begin{array}{l}\text { Eree } \\
\text { Trapped }\end{array}$ & $\begin{array}{l}0.67 \\
7.53\end{array}$ & 25 wt $\&$ KTPB \\
\hline$U F^{5}$ & $\begin{array}{l}\text { Free } \\
\text { Trapped } \\
\text { Trapped } \\
\text { Trapped }\end{array}$ & $\begin{array}{l}-.- \\
6.7 \\
1.1 \\
0.6\end{array}$ & $\begin{array}{l}\text { high soluble salts, high dose, } 10 \text { wto } \\
\text { no increase in benzene with dose } \\
\text { initial production rate } \\
\text { after half-year dose } \\
\text { after } 2-y r \text { dose }\end{array}$ \\
\hline
\end{tabular}

This work.

2 Appendix $C$.

3 Appendix A, p.11.

4 Reference 2 .

5 Reference 3. 
EIGURE 1

Loss of KTPB Due to Radiolysis

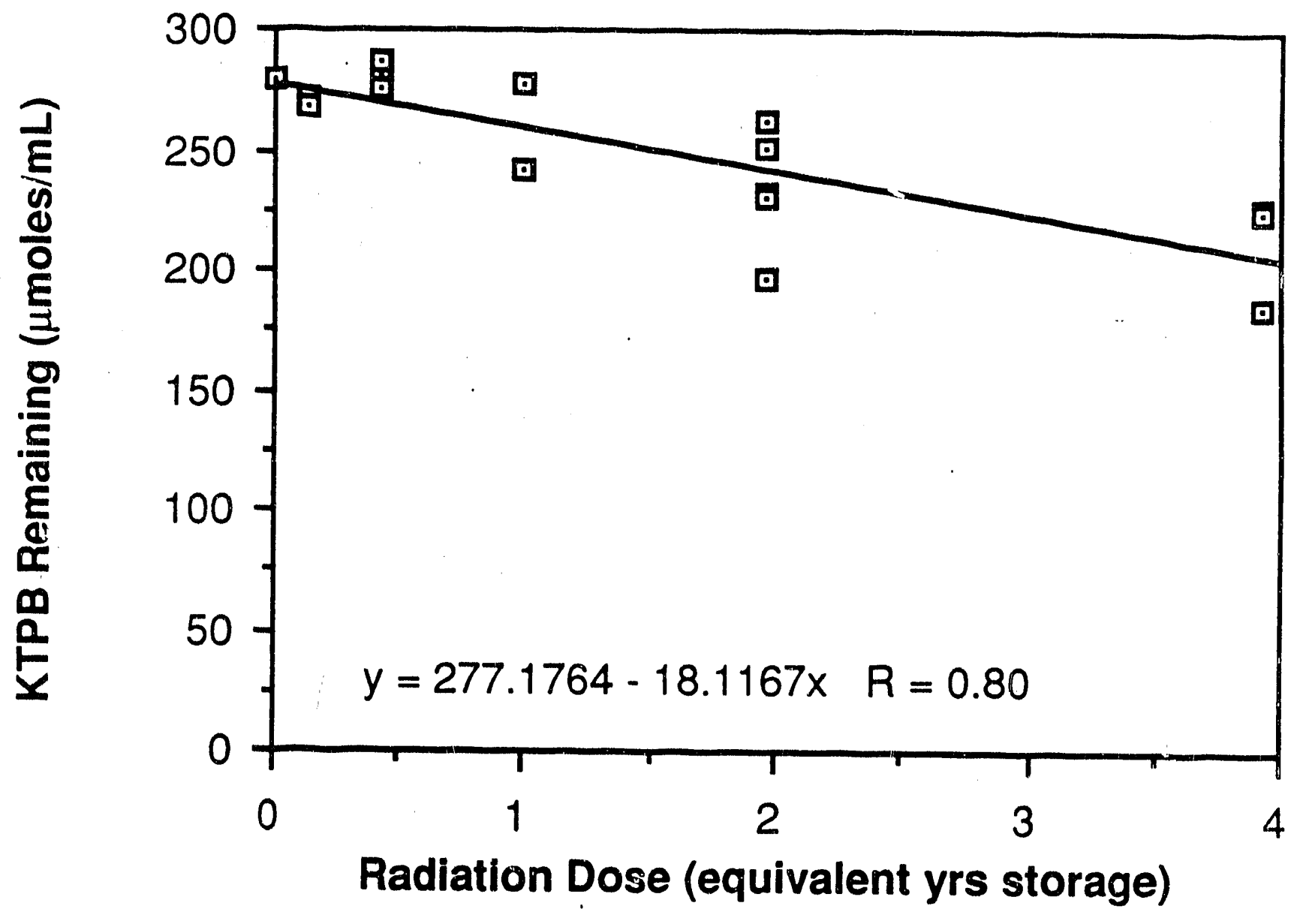


FIGURE 2

Berizene Formation in 10 weight \& KTPB Slurry

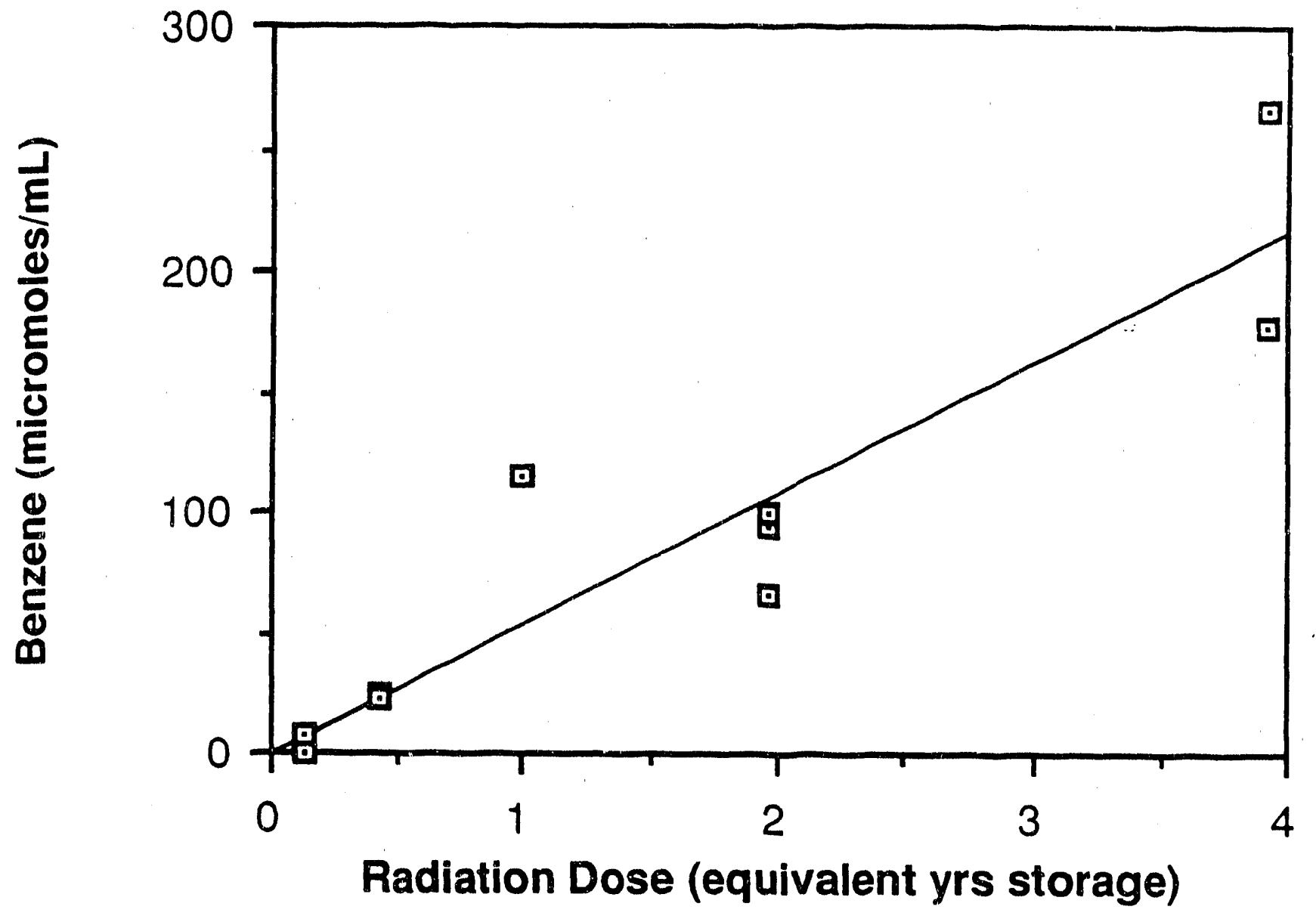


FIGURE 3

Phenol Formation in 10 weight of KTPB Slurry

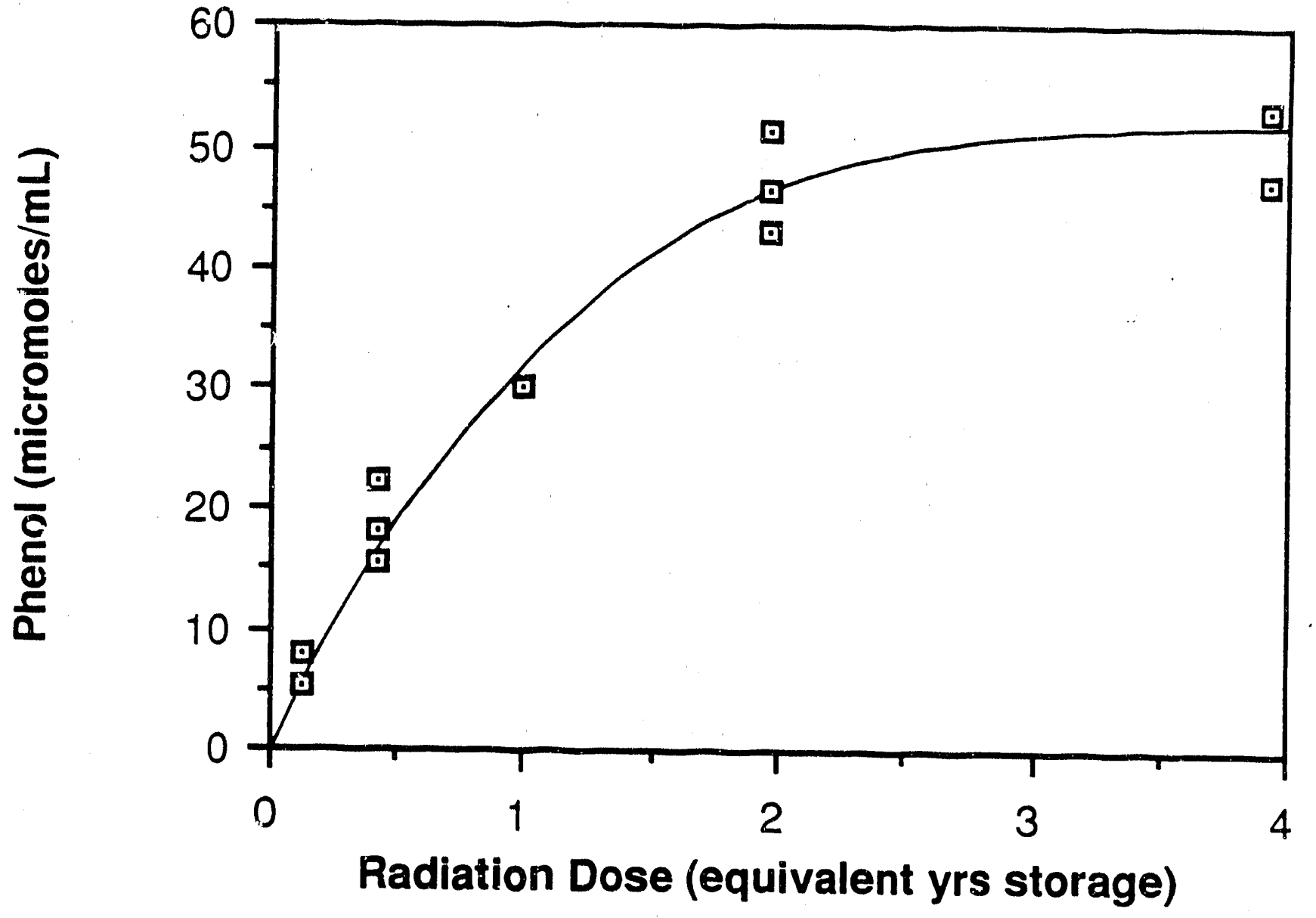


FIGURE 4

Biphenyl Formation in 10 weight of KTPB Slurry

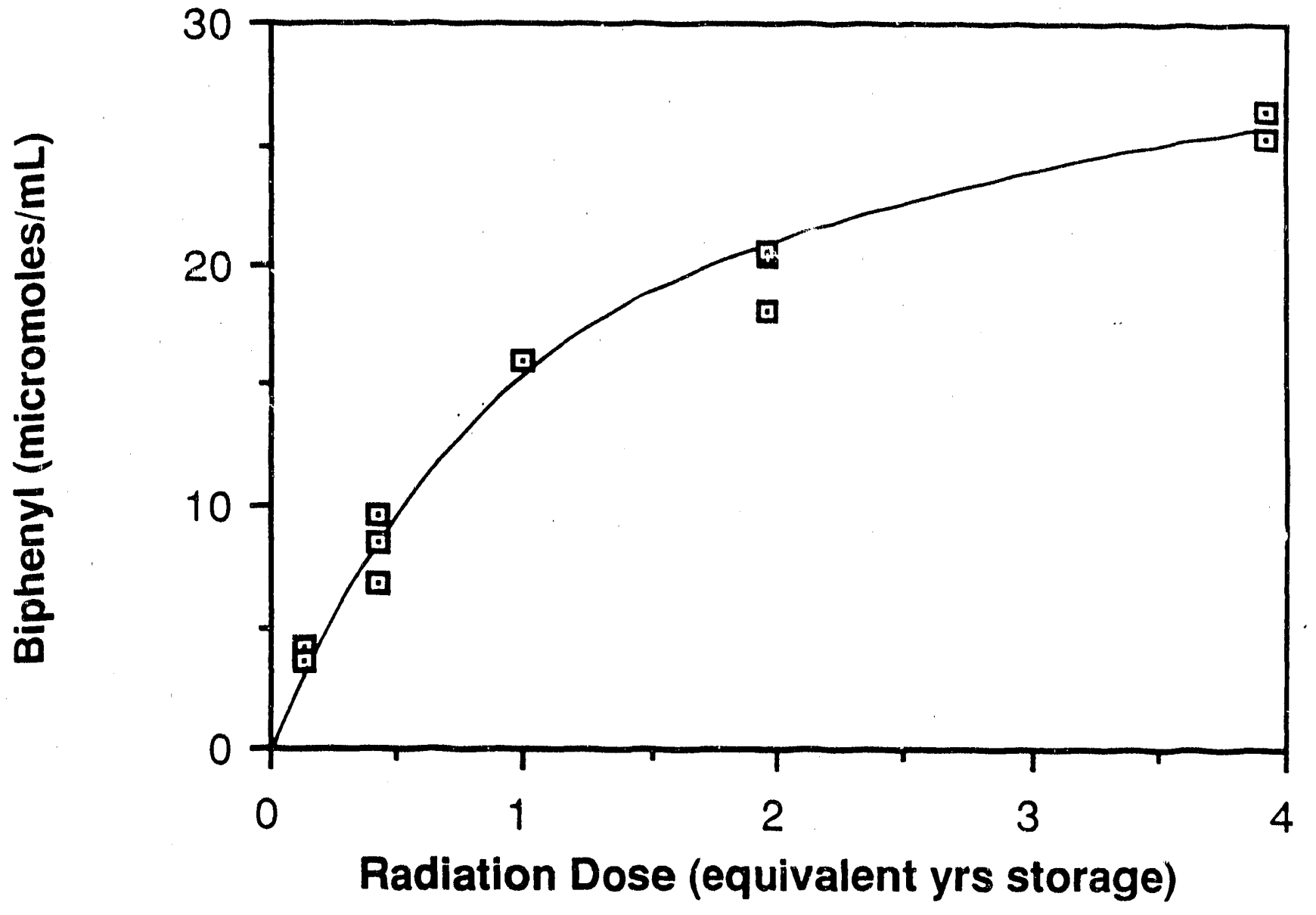


FIGURE 5

Phenylboric Acid (PBA) Formation in 10 weight of KTPB Slurry

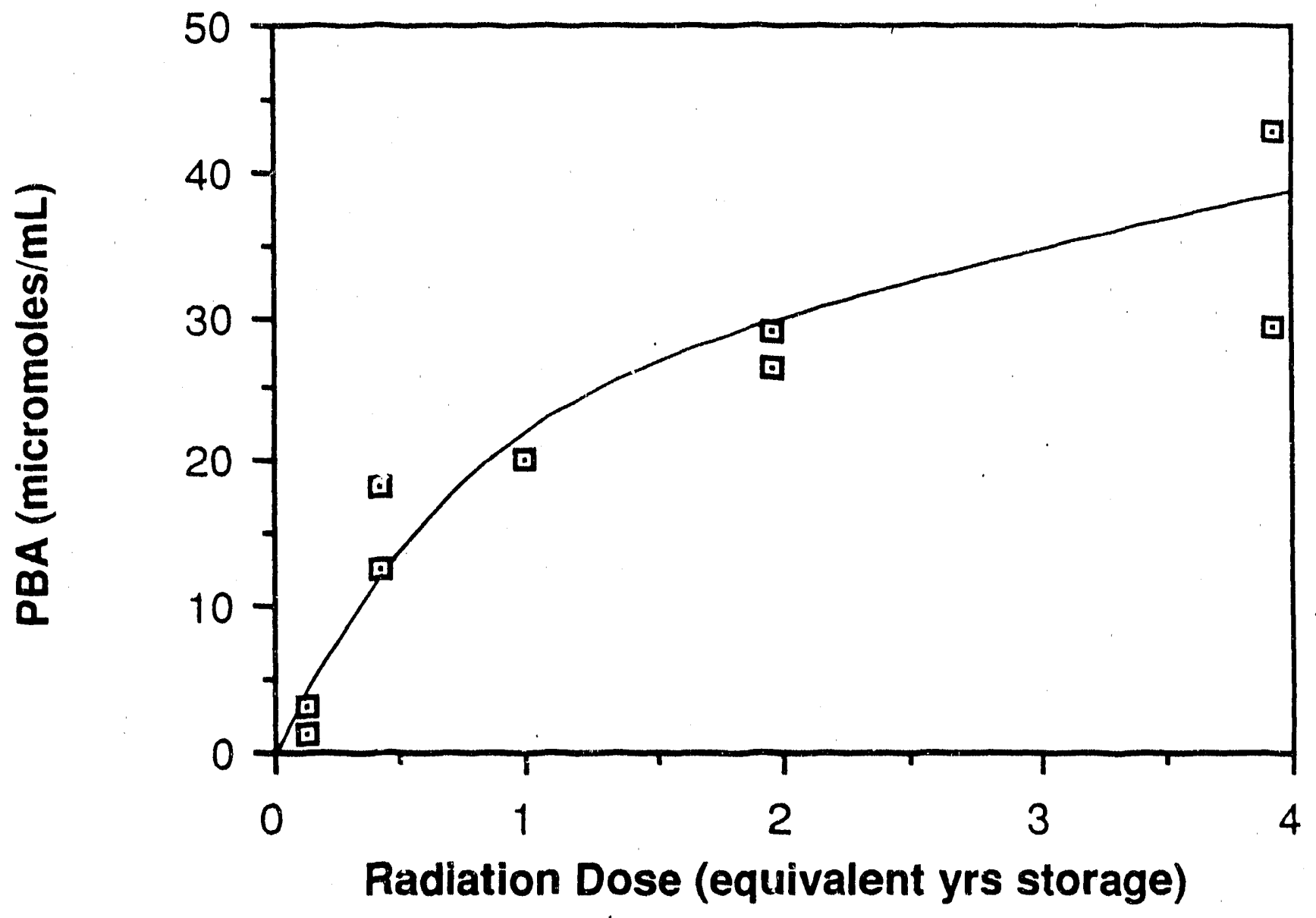


EIGURE 6

pH Changes During Radiolysis of a 10 Weight $\&$ KTPB Slurry

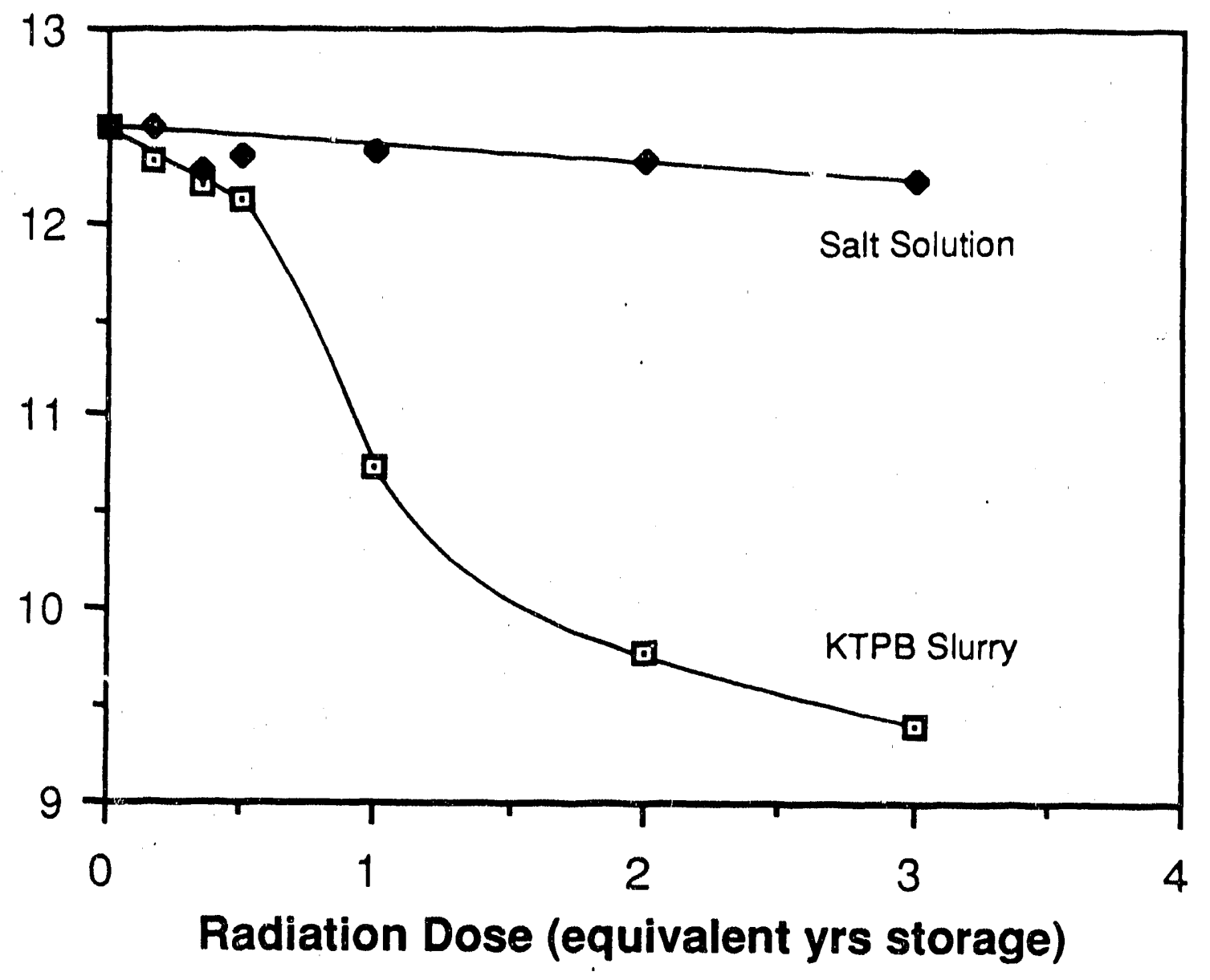


Appendix A

Report from University of Florida

Dated November 4, 1985 


\section{Report $A$}

November 4, 1985

THE RADIOLYSIS OP WASEED TETRAPBENYLBORATE SLURRY CONTAINING $\mathrm{Na}^{+}, \mathrm{OH}^{-}, \mathrm{NO}_{2}^{-}$, and $\mathrm{NO}_{3}^{-}$IONS

Avinash R. Gupta and Robert J. Hanrahan

Department of Chemistry

Oniversity of Florida

Gainesvilie, FL 32611

In an earlier report (1) submitted February 1, 1985, and in the manuscript of the paper (2) presented at the $189 t h$ ACs National Meeting at Miami, Florida, April 28 - May 3, 1985, the results of the radiolysis of unwashed soluble and insoluble tetraphenylborate precipitate in the presence of $\mathrm{NaOH}, \mathrm{NaNO}_{2}$, and $\mathrm{NaNO}_{3}$ salt solution were submitted. The concentration of the ions. were as follows $\mathrm{Na}^{+}, 5.6 \mathrm{M}^{+} \mathrm{NO}_{3}^{-}, 3.3 \mathrm{M} ; \mathrm{NO}_{2}^{-}, 1.0 \mathrm{M}$; and $\mathrm{OB}^{-}, 1.3 \mathrm{M}$. The object of the current project was to identify qualitatively and quantitatively the products that are formed during the radiolysis of washed tetraphenylborate precipitate containing $\mathrm{Na}^{+}, \mathrm{OH}^{-}, \mathrm{NO}_{2}^{-}$, and $\mathrm{NO}_{3}^{-}$ions. The washed slurry was sent by Dr. D.D. Walker from savanah River plant. The amount of tetraphenylborate precipitate left after irradiation was measured in both unwashed and washed tetraphenylborate precipitates. Experiments are in progress to study the effect of dose rate on the product yields in the radiolysis of washed tetraphenyiborate slurries. 
An ISCO high pressure liquid chromatograph with a $\mathrm{v}^{4}$ variable wavelength absorbance detector was used to identify the radiolysis products. Three new products that were previously unidentified bave been identified in the radiolysis of unwashed terraphenylborate precipitates in the presence of $\mathrm{NaOH}, \mathrm{NaNO}_{2}$, and $\mathrm{NaNO}_{3}$ salt solution. These products are being separated using column chromatography and will be confirmed using NMR and massspectometry.

\section{EXPERIMENTAL}

Radiolysis experiments were carried out on samples which were sent from Savannah River Plant by Dr. D.D. Walker. Samples consisting of $1 \mathrm{ml}$ air saturated slurries of nominal 10 wt (actually 6 wt according to our measurements) washed teraphenylborate precipitate containing $\mathrm{Na}^{+}, \mathrm{OH}^{-}, \mathrm{NO}_{2}^{-}$, and $\mathrm{NO}_{3}^{-}$ lons were taken in a $13 \mathrm{~mm}$ ground glass stoppered test tube using a hypodermic syringe. These samples were irradiated in a co-60 gama source for different time periods up to 60 days corresponding to a dose of about 450 mega rads. The calculated dose rate (higher) was $1.90 \times 10^{19} \mathrm{ev} \mathrm{m}^{-1} \mathrm{hr}^{-1}$ in Fricke solution, on August 1, 1985. This dose rate will be referred to as the "Higher" dose rate value in contrast to other experiments conducted at a "Lower" dose rate, to be described later. The calculated dose rate (lower) was $6.5 \times 10^{18} \mathrm{eV} \mathrm{ml}^{-1} \mathrm{hr}^{-1}$, on August $1,1985$. 
After irradiation, 1 ml of water was added to the radiolysis mixture. The mixture was then shaken with lml of cyclohexane, and 10 microliters of the cyclohexane extraction was injected into the Isco high pressure liquid chromatograph. The aromatic products were separated using a whatman ODS-3 (Octadecylsilane) columi $(25 \mathrm{~cm} \times 4.6 \mathrm{~mm}$ i.j.). A guard column was used, the material of which was changed after every two analyses. A mixture of 758 acetonicrile in water was used as the mobile phase, the flow rate of which was adjusted to $1.1 \mathrm{ml} / \mathrm{min}$. The ultraviolet absorbance detert ir was set to $254 \mathrm{~nm}$; the output of the detector was fed to a $10 \mathrm{mV}$ potentiometric recorder, with a chart speed of $2 \mathrm{~cm} / \mathrm{min}$.

The aqueous layer and the cyclohexane layer were decanted from the solid tetraphenylborate and the solid was dissolved in 5 ml of acetonitrile so as to release the trapped products into the. solution. Ten microliters of this solution was then injected into the high pressure liquid chromatograph for analysis of the trapped products.

The tetraphenylborate peak that occurs in the experiment described in the previous paragraph is off scale. In order to analysis the amount of solid tetaphenylborate precipitate left after irradiation, 200 microliters of the dissolved tetraphenylborate solution was taken in a test tube and diluted with $1 \mathrm{ml}$ of acetonitrile. Ten microliter of the diluted solution was then injected in the APLC for analysis of the residual teraphenylborate. 


\section{Effect of Gamma Des= Rate}

Experiments are in progress to study the effect of dose rate on the the yield of the products in the radiolysis of washed tetraphenylborate slurries. Samples consisting of $1 \mathrm{ml}$ of the Fricke dosimeter solution were irradiated in $13 \mathrm{~mm}$ ground glass stoppered test tubes. An aluminum sample holder was used to assure reproducible positioning of the test tubes. The sample holder consists of a central $11 / 16$ inch $(1.7 \mathrm{~cm})$ diameter hole for the gamma source rod surrounded by two concentric rings with six sample hole positions per ring. The inner ring of the sample positions is approximately on a $1^{1 / 4}$ inch $(3.1 \mathrm{~cm}$ ) diameter circle, while the outer holes are on a $2 \frac{1}{2}$ inch $(6.4 \mathrm{~cm})$ diameter circle. The sample holes ascommodate $13 \mathrm{~mm}$ diameter (O.D.) test tubes (preferably $-0.2 \mathrm{~mm}$ minimum size, $+0.0 \mathrm{~mm}$ maximum size). Most of the experiments were done using the samples in the inner ring. To study the effect of dose rate the samples were also irradiated in the outer position of the sample holder. The dose rate at the outer position is one third the dose rate at the inner position. Irradiation of the fricke solution was carried out in the absence and presence of NaCl, used to diagnose possible organic contamination. Optical densities were measured on a Beckman spectrophotometer at a wavelength of 305 millmicrons.

Samples consisting of 1 ml of Fricke dosimeter sulution were irradiated in 13 mm test tubes with ground glass stoppers. The samples were kept in the outer positions of the sample holder. 
Figures 1 and 2 show the plots of of the optical densities versus irradiation time in the presence and absence of Nacl. The calculated dose rate at the inner (higher dose rate) and outer (lower dose rate) positions of the sample holder were as follows, $1.9 \times 10^{19} \mathrm{eV} \mathrm{mil}^{-1} \mathrm{hr}^{-1}$ and $6.5 \times 10^{18} \mathrm{eV} \mathrm{ml}^{-1} \mathrm{hr}^{-1}$, respectively.

Radiolysis experiments at a lower dose rate were carried out in the same fashion as the radiolysis experiments at a higher dose rate, as explained earlier in the experimental section.

\section{RESULTS}

Experiments were carried out to study the effect of long term gamma irradiation on the 6 wt washed slurries. Irradiation was carried out at a bigher dose rate for a period of approximately 60 days, equivalen to a maximum dose of about 450 mega rads which corresponds to a storage period of the tetraphenylborate precipitate at the Savannah River plant for 3.1 years.

Figures 3 and 4 whow the yields of nitrobenzene and biphenyl analyzed from the cyclohexane extraction of the aqueous layer as a function of irradiation time at the higher and lower dose rate. At the higher dose rate the yield of nitrobenzene reaches a maximum value of $4.0 \times 10^{-7}$ moles/ml at about 40 days and then drops off. Irradiation time of 40 days at a bigher dose rate corresponis to a dose of about 300 mega rads. At the lower dose 
rate the yield of nitrobenzene is linear witn $\equiv \approx s-$ ibed dose up to at least 100 mega rads. The yleld of nitrobenzene at the lower dose rate is greater than that at the higer dose rate. The yield of biphenyl drops off as the irradiation timc increases, and as seen from figure 4 the yield of biphenyl at the lower dose rate is much higher than the yield at higher dose rate. Experiments corresponding to higher (total) doses at the lower dose rate are in progress.

The remaining solid was thon dissolved in $5 \mathrm{ml}$ acetonitrile and analyzed. Benzene and biphenyl were the major products. Figures 5 and 6 show plots of the yields of trapped benzene and trapped biphenyl as a function of irradiation time, when the solid is dissolved in acetonitrile. Initially, at the higher dose rate, the yield of trapped benzene increases with irradiation time, reaches a maximum yield of $50 \mathrm{micromoles} / \mathrm{ml}$ at 30 days and then falls off. Irradiation time of 30 days corresponding to a dose of about 220 mega rads. At the lower dose rate the yield of benzene is linear with dose up to at least 100 mega rads. At the higher dose rate the yield of trapped biphenyl increases linearly with irradiation time up to about 40 days corresponding to a dose of 300 mega rads and then remains essentially constant with a maximum yield of $12.1 \mathrm{micromoles} / \mathrm{ml}$. At the lower dose rate the yield of trapped biphenyl is almost linear with dose up to at least 60 mega rads. Table 1 shows the G-values of the products formed in the radiolysis of 6 wt tetraphenylborate at the two values of the dose rate. 
Figure 7 shows the yield of residual tetraphenylborate versus irradiation time. The amount of tetraphenylborate ifradiated in each of the radiolysis experiments was $1.4 \times 10^{-4}$ moles/ml. At a higher dose rate the amount of residual tetraphenylborate left after 60 days, corresponding to a total dose of about $450 \mathrm{mega}$ rads was $0.90 \times 10^{-4} \mathrm{moles} / \mathrm{ml}$, indicating that 388 of the solid tetraphenylborate was converted into various products. At a lower dose rate the amount of residual tetraphenylborate left after 40 days corresponding to a total dose of about $100 \mathrm{mega} \mathrm{rad}$ was $1.30 \times 10^{-4} \mathrm{moles} / \mathrm{ml}$, indicating that 118 of the solid tetraphenylborate was converted into various products. Table 2 compares the amount of tetraphenylborate converted into products using higher and lower dose rates. Table 3 shows a comparison of the G-values of the products (immediate release and trapped in crystal) in the radiolysis of unwashed and washed tetraphenylborate slurries at high and low dose rates.

Earlier results had much higher $\mathrm{OB}^{-}, \mathrm{NO}_{3}^{-}$, and $\mathrm{NO}_{2}^{-}$ concentrations therefore the yields of the products in the earlier experiments and the present experiments are considerably different. Also, the unwashed precipitate that was irradiated was 10 wts as compared to the 6 wt8 washed precipitate that was irradiated in the present experiments. Solutions resulting from long term irradiation of the unwashed precipitate had a much darker yellow color when dissolved in acetonitrile indicative of larger yields of nitrate or nitrite species. Also, product yields at the lower dose rate are somewhat different than the 
product $y i \in l d s$ at the higher dose rate except for the total destruction of RTPB at both the dose rates are the same.

The three new minor products, previously unidentified are oterphenyl, m-terphenyl, and p-terphenyl. G-values are estimated as not greater than 0.001 . 
Table 1

G-Value of Products (Immediate Release) in the Radiolysis of 6 wt Tetraphenylborate slurries.

Product Higher Dose Rate Lower Dose Rate

$\begin{array}{lll}\text { Nitrobenzene } & G_{\text {initial }}=0.0019 & G=0.0064 \\ \text { Biphenyl } & G_{\text {initial }}=>0.033 & G=0.060\end{array}$

G-Value of Products (Trapped in Crystal) in the Radiolysis of 6 wt is Tetaphenylborate slurries.

Product

Bigher Dose Rate

Lower Dose Rate

Benzene

$G_{\text {initial }}=0.31$

$G=0.47$

Bipheny 1

$G_{\text {initial }}=0.0^{* 1}$

$G_{\text {initial }}=0.079$ 


\section{Table 2}

Comparison of the Amount of Tetraphenylborate Converted into Products in the Radiolysis of 6 wt Tetraphenylborate slurries using Bigher and Lower Dose Rates.

Dose Rate

Total Dose Mega Rads
8 Conversion

38

11 
Table 3

Comparison of. the G-Values of the Products (Immediate Release and Trapped in Crystal) in the Radiolysis of Unwashed and Washed Tetraphenylborate Slurries at High and Low Dose Rates.

Unwashed Precipitate

Bigher Ion concentration

(10 wts Solid)
Washed Precipitate

Lower Ion Concentration

(6 wts Solid)

High Dose Rate

High Dose Rate

Low Dose Rate

$\begin{array}{lll}\text { (a) } & \text { (b) } & \text { (b) }\end{array}$

(b) (b)

(b) (b)

(b) (c)

(c)

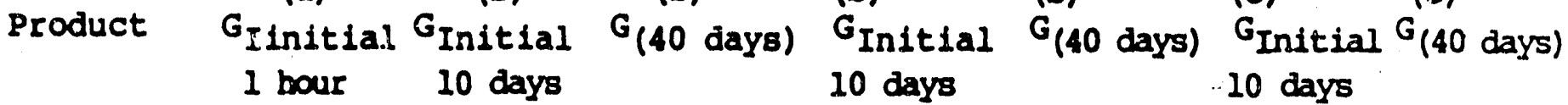

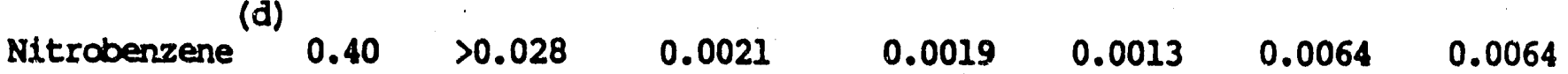

(d)

Biphenyl

1.6

0.20

0.20

$>0.033$

$0.0050>0.27$

0.060

(e)

Benzene

$6.7 \quad 1.08$

0.60

0.31

0.16

0.47

0.47

$(\epsilon)$

Biphenyl

0.44

0.12

0.060

0.044

0.038

0.079

0,068

(a) Short term irradiation. Maximum irradiation time 8 hours corresponding to a maximum dose of 2.7 megarads.

(b) Long term irradiation. Maximum irradiation time 60 days corresponding to 450 megarads at higher dose rate.

(c) Long term irradiation. Maximum irradiation time 40 days corresponding to a maximum dose of 100 megarads at lower dose rate.

(d) Immediate $t$ is 18

(e) Trapped in crystal 


\section{REFERERCES}

1) A.R. Gupta and R.J. Hanrahan, Whe Radiolysis of Tetraphenylborate in the Presence of Alkaline $\mathrm{NaOH}, \mathrm{NaNO}_{2}$, and $\mathrm{NaNO}_{3}$ Salt Solution". Report 2, February 1, 1985.

2) A.R. Gupta, RoJ. Banrahan, and D.D. Walker, "Ose of Co-60 Gamma Irradiation to Simulate the Decomposition of Tetraphenylborate Precipitates from High Level Radioactive Waste". Report 3, Presented at the 189th ACS National Meeting, Mlami, Florida, April 28 - May 3, 1985. 


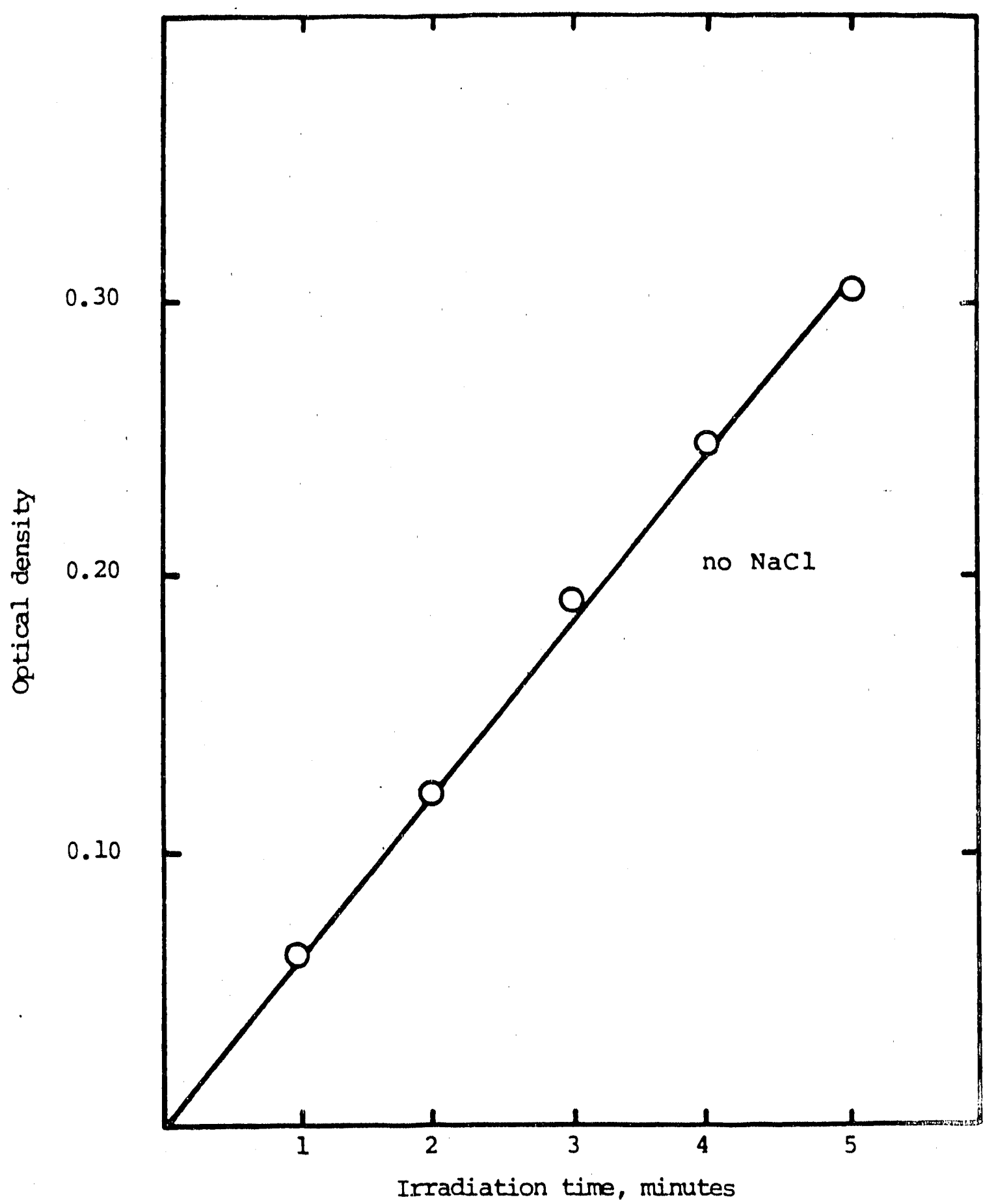

Fig. 1 Dosimetry: Optical density versus irradiation time ( $1 \mathrm{ml}$ solution). Outer position of the co-60 irradiator sample holder. 


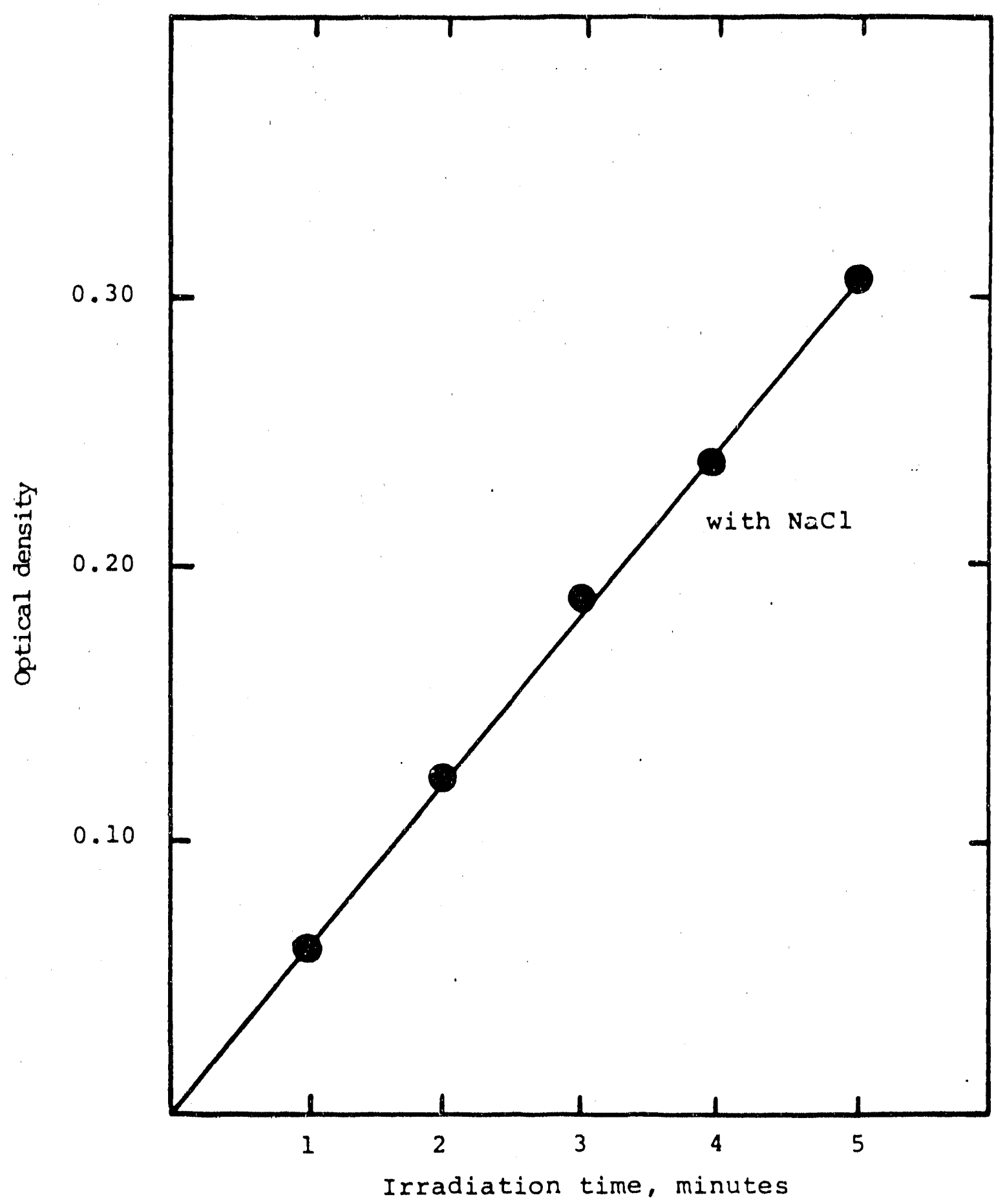

Fig. 2 Dosimetry: Optical density versus irradiation time (1 $\mathrm{ml}$ solution). Outer position of the co-60 irradiator sample holder. 


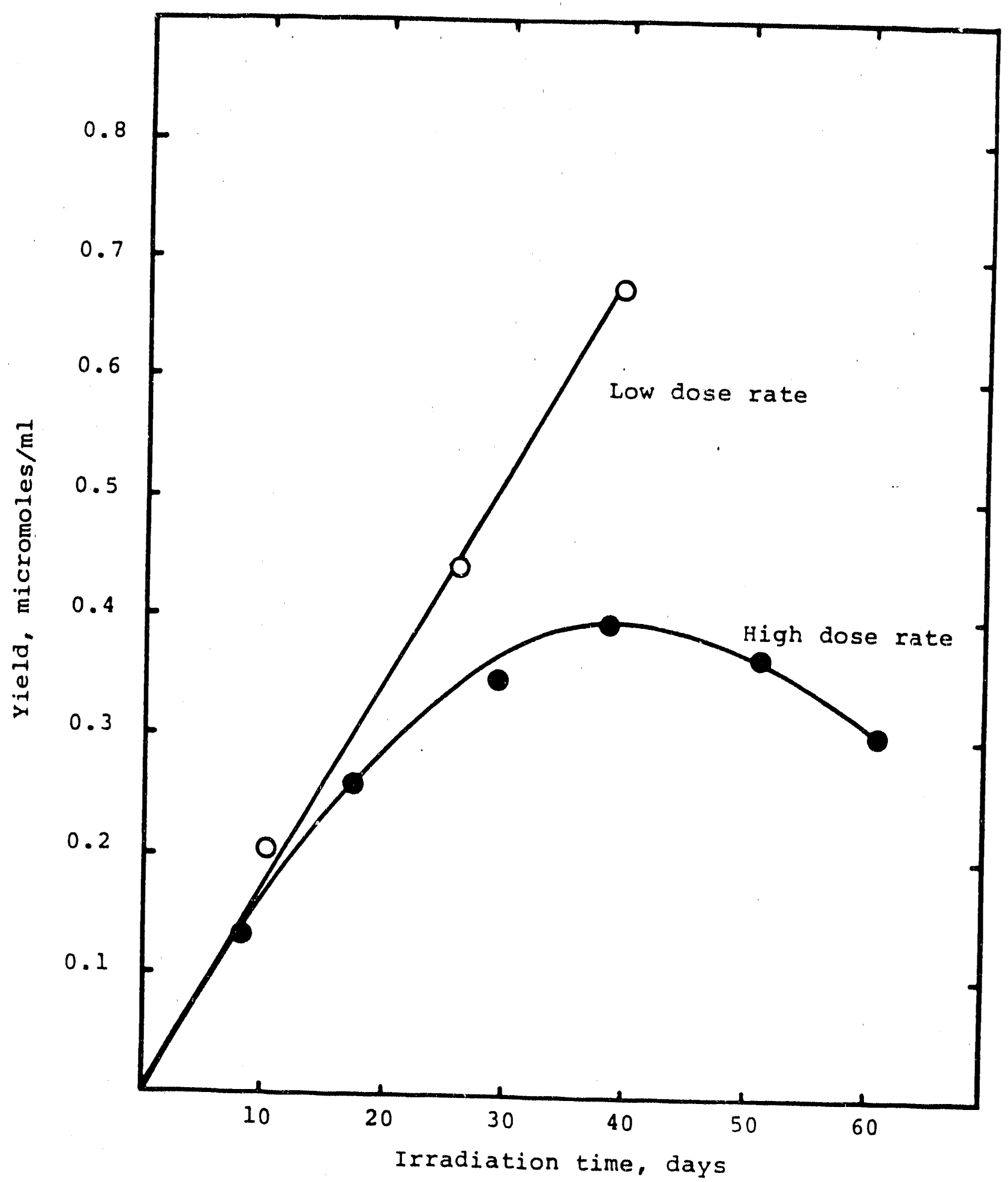

Fig. 3 Production of nitrobenzene versus radiolysis time in the radiolysis of tetraphenylborate. Nitrobenzene extracted from aqueous layer into cyclohexane for analysis. 


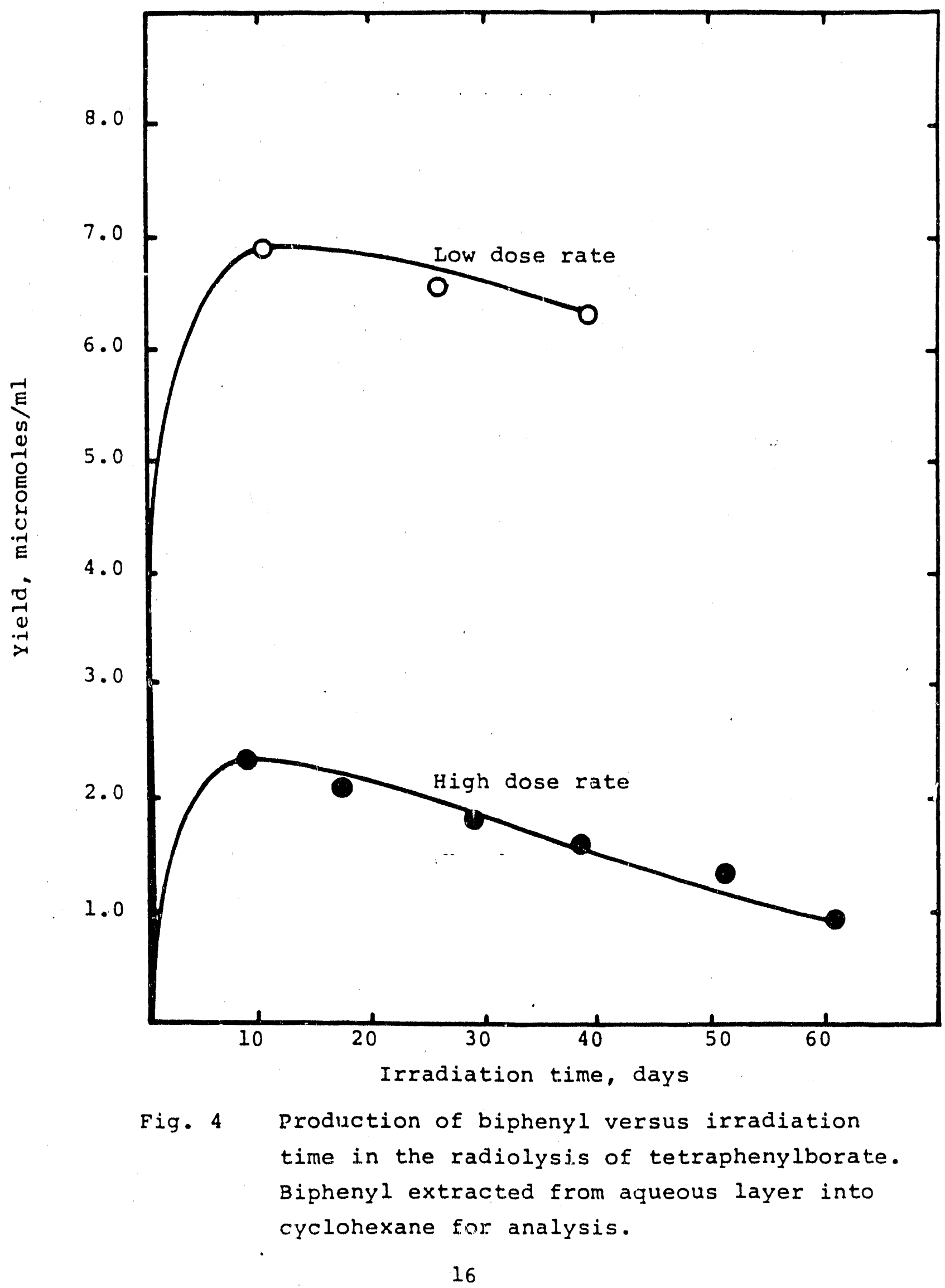




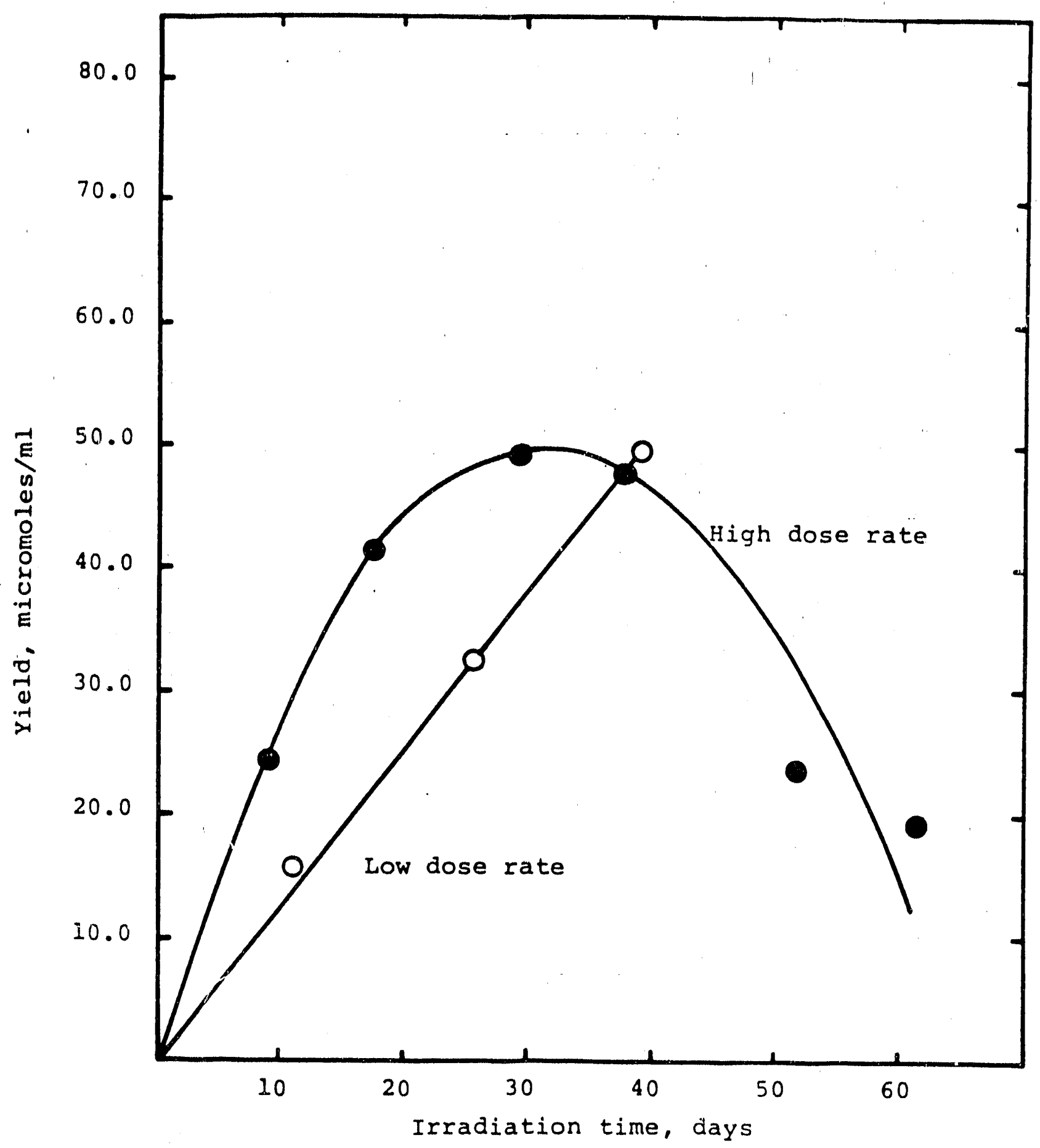

Fig. 5 Production of benzene versus irradiation time in radiolysis of tetraphenylborate. Benzene was analyzed after dissolving the solid in $5 \mathrm{ml}$ acetonitrile. 


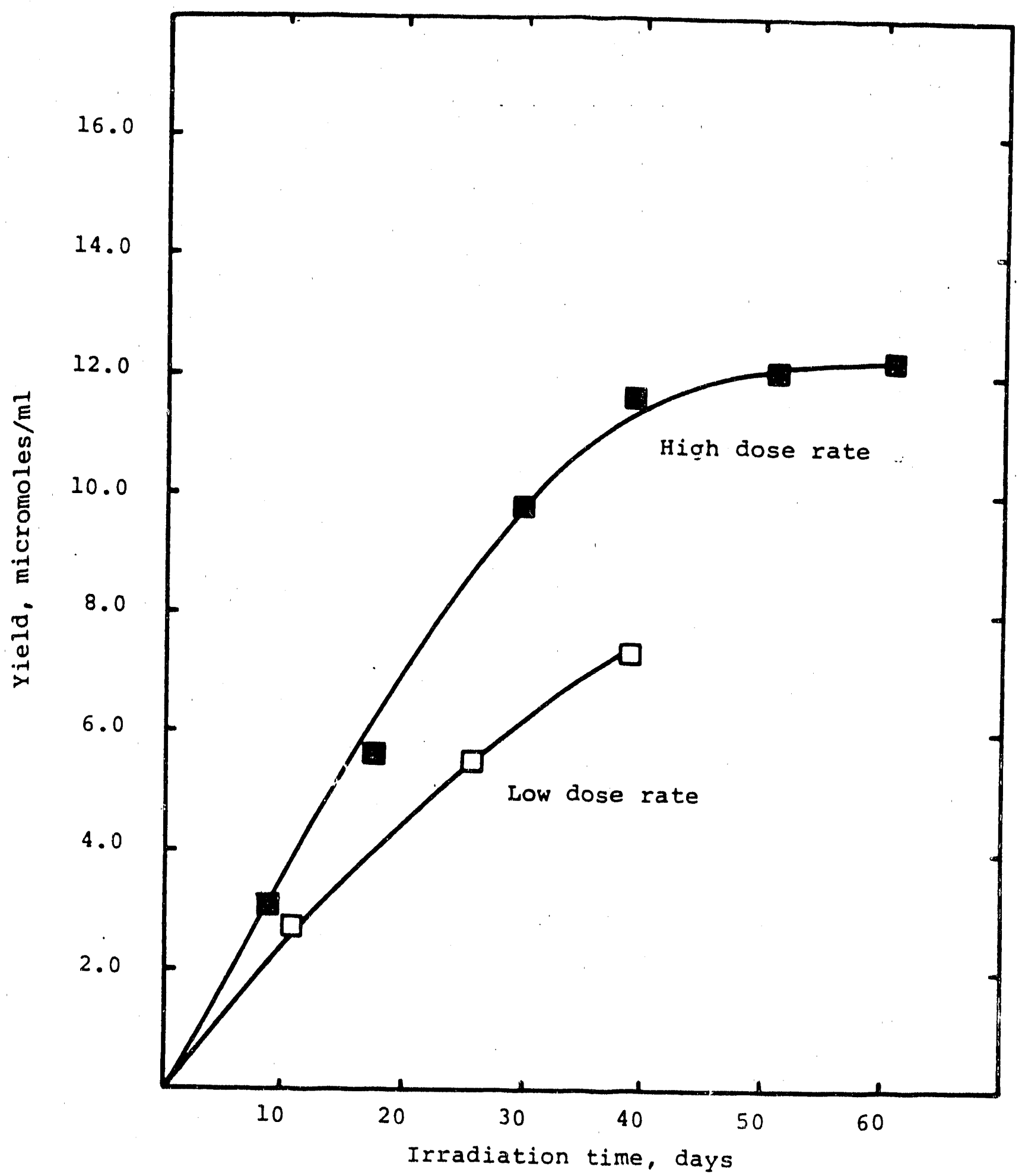

Fig. 6 Production of biphenyl versus irradiation time in the radiolysis of tetraphenylborate. Biphenyl was analyzed after dissolving the solid in $5 \mathrm{ml}$ acetonitrile. 


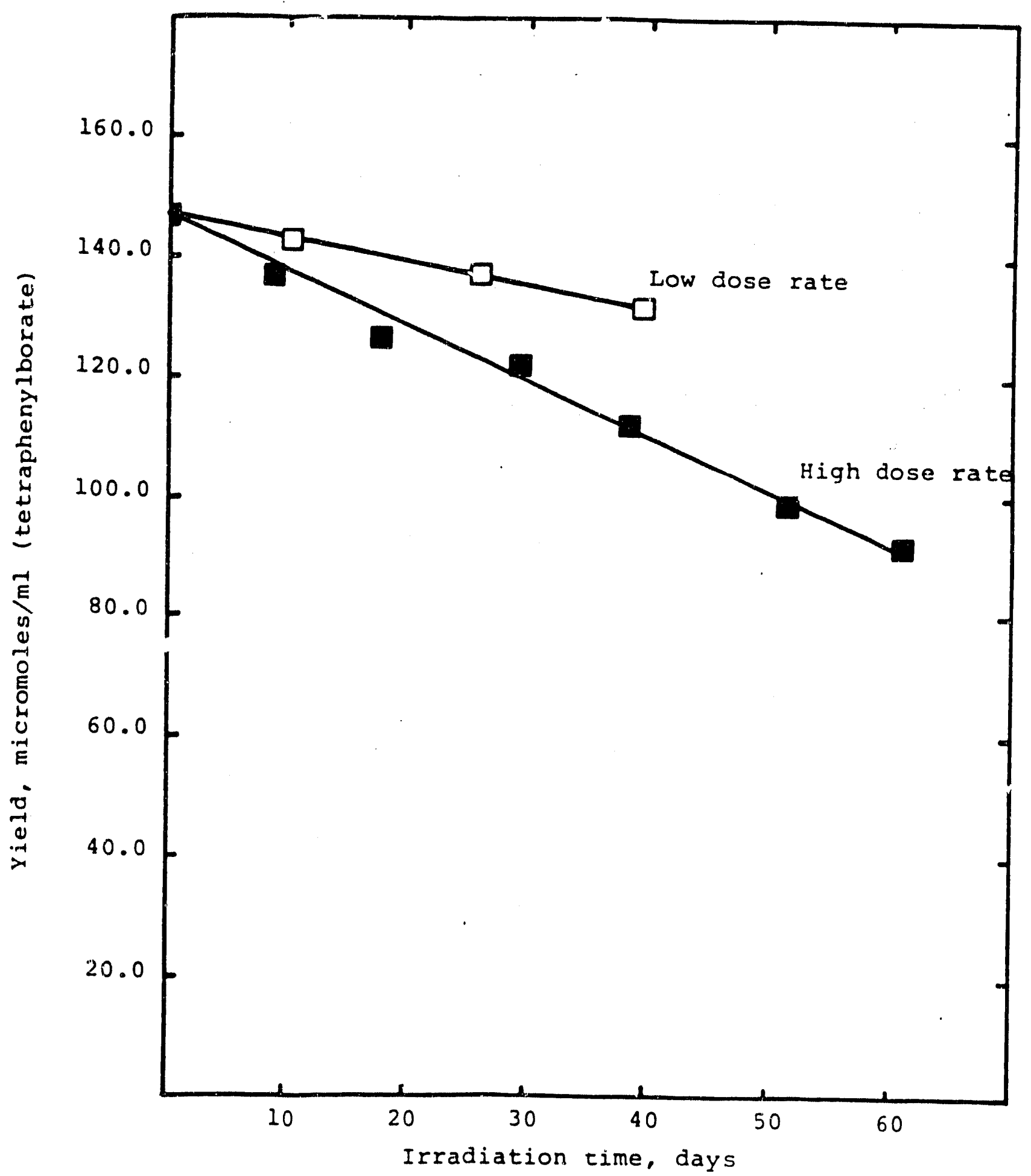

Fig. 7 Residual tetraphenylborate versus irradiation time in the radiolysis of tetraphenylborate. The tetraphenylborate was analyzed after dissolving the solid in actonitrile. 
Calculation of Dose Rate to Stored KTPB Precipitate Slurry

The following assumptions are made in the calculation of the radiation dose to the stored slurry:

- The radiation dose can be approximated by considering only the Cs-137 in the precipitate. The $\mathrm{Sr}-90$ is ignored since it contributes very little to the total number of curies in the slurry.

- All of the decay radiation is absorbed by the precipitate. This ignores any radiation energy deposited in the walls or airspace of the storage. For a large diameter tank filled several feet deep with slurry, this is a good approximation.

- The Cs-137 concentration is 36 Curies/gallon of 10 weight o slurry. This estimate is obtained from the current material balance for the DWPE process (Ref. 8).

- The decay of $\mathrm{Cs}-137$ and Ba-137 produces 4.84 watts per kilocurie.

- A 10 weight of slurry has a density of $1.0 \mathrm{~g} / \mathrm{mL}$.

The method of calculation is:

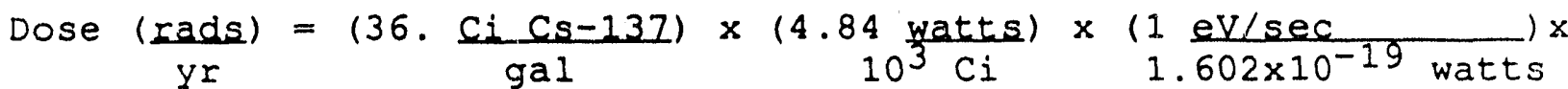

$\left(\frac{1 \mathrm{rad}}{6.24 \times 10^{13} \mathrm{eV} / \mathrm{g}}\right) \times\left(\frac{1 \mathrm{~mL})}{1 \mathrm{~g}} \times\left(\frac{1 \mathrm{gal}}{3,785.4 \mathrm{~mL}}\right) \times\right.$

$\left.\frac{\left(3.15 .36 \times 10^{7}\right.}{y^{r}} \sec \right)$

$=1.45 \times 10^{8} \mathrm{rads} / \mathrm{yr}$ 


\section{Appendix C \\ Calculation of Dose Rate in Tank 48}

A major uncertainty in the interpretation of data from the Tank 48 demonstration has been the calculation of the dose rate and how it compares to the CPES "average" slurry composition. In a previous report, a G-value was calculated for the benzene production in that tank using $130,000 \mathrm{Ci}$ of $\mathrm{Cs}-137$ and 10,000 pounds of KTPB. An error in the cesium concentration in the Tank 24 salt solution used for the Tank 48 demonstration has recently been found, and a higher estimate of the Tank 48 dose rate has been calculated.

The previous estimate in the cesium in Tank 48 was based on the volume of salt solution transferred from Tank 24 and the Cs-137 concentration in the liquid. The volume was 427,000 gallons, measured to \pm 300 gallons using reel tapes in Tank 24 (Ref. 7). The concentration of cesium in the salt solution was obtained by averaging the Cs-137 found in samples $1 \mathrm{AP}$ and $1 \mathrm{BP}$, as reported in Reference 9. These two samples were taken from Tank 24 or the transfer line during the actual transfer to Tank 48 . However, an error in ono of the reported numbers has been found after a recheck of the original analyses, recorded in "In Tank Demonstration, Data Book \#3" and maintained by B. A. Hamm. The originally reported and the new values are listed below:

\begin{tabular}{|c|c|c|}
\hline Sample & $\begin{array}{l}\text { Cesium-137 Cor } \\
\text { Beported in Ref. } 9\end{array}$ & $\begin{array}{l}\text { ration }(\mathrm{nCi} / \mathrm{mL}) \\
\text { corrected value }\end{array}$ \\
\hline $1 \mathrm{AP}$ & $1.3 \pm .1 \times 10^{5}$ & $1.3 \pm .1 \times 10^{5}$ \\
\hline $1 B P$ & $3.5 \pm .3 \times 10^{4}$ & $1.41 \pm .03 \times 10^{5}$ \\
\hline
\end{tabular}

The number of curies of Cs-137 in Tank 48 is obtained by the following calculation:

Curies of $\left.\mathrm{Cs}-137=(427,000 \mathrm{gal}) \times \frac{(3785.4 \mathrm{~mL}}{\mathrm{gal}} \times \frac{\left(1.35 \times 10^{-4}\right.}{\mathrm{mL}} \mathrm{Ci}\right)$ $=2.2 \times 10^{5}$ Curies $\left( \pm 0.1 \times 10^{5}\right)$

The amount of $\mathrm{Cs}-137$ removed from Tank 48 in the decontaminated filtrate and wash water can also be calculated from information in References 7 and 9. However, this is a negligably small portion, amounting to only $10 \mathrm{Ci}$.

The radiation dose to the slurry, assuming no energy losses to the walls or airspace, is given by:

$$
\begin{aligned}
\text { Dose rate } & \left.=\left(2.2 \times 10^{5} \mathrm{Ci} \text { of Cs-137) } \times \frac{(4.84 \text { watts }}{\mathrm{kCi} \text { of Cs-137 }}\right) \times \frac{(1 \mathrm{eV} / \mathrm{sec}}{1.6 \times 10^{-19} \text { watts }}\right) \\
& =6.7 \times 10^{21} \mathrm{eV} / \mathrm{sec}
\end{aligned}
$$

There are currently 62,000 gallons of slurry stored in Tank 48 . The configuration of the slurry is approximately a disk 85 feet in diameter and 17.7 inches thick. Calculations of the fraction of energy lost to the walls and airspace using infinite cylinder and 
infinite slab models indicate that more than $95 \%$ of the beta and gamma energy from the decay of Cs-137 is absorbed by the solution.

Using the dose rate above and the known evolution rate for benzene from Tank 48 (Ref. 3), it is possible to calculate a G-value for "free" benzene. This calculation was made in Reference 3 but using the incorrect cesium concentration. The correct calculation is:

(Note: $2.7 \pm 1.0 \mathrm{ppm}$ benzene by volume is $0.0027 \mathrm{ml} / \mathrm{L}$ )

$$
\begin{aligned}
G(\text { benzene })= & \left.\left.\frac{(0.0027 \mathrm{~mL})}{1000 \mathrm{~mL}} \times \frac{\left(330 \mathrm{ft}^{3}\right.}{\mathrm{min}}\right) \times \frac{1 \mathrm{~mole}}{22.4 \mathrm{~L}} \times \frac{(28.3 \mathrm{~L}}{\mathrm{ft}^{3}} \times\right) \\
& \frac{\left(6.02 \times 10^{23} \mathrm{molecules} / \mathrm{mole}\right)}{6.7 \times 10^{2} 1} \mathrm{eV/ \textrm {sec }} \frac{(1 \mathrm{~min})}{60 \mathrm{sec}} \\
= & 0.17 \text { molecules }( \pm 0.06)
\end{aligned}
$$

An easy way to compare the Tank 48 results with those expected from full scale operations is to estimate the equivalent amount of 10 wt o KTPB slurry currently in the tank. This may be obtained from a material balance froin the In-Tank Demonstration, given in Table $C$. At the end of the third wash, there was approximately 9500 lbs of NaTPB which had been converted to 9900 lbs of KTPB in Tank 48. There were also 2100 lbs of sodium titanate in the tank (Ref. 7). Assuming it was concentrated to $10 \mathrm{wt}$ of solids, there would be 14,400 gallons of 10 wt of slurry and it would contain $15 \mathrm{Ci}$ of Cs-137 per gallon ( 428 of the CPES "average" slurry). Although the original Tank 24 salt solution was $6 \mathrm{X}$ lower than "average" in Cs-137, it was also $2 x$ lower in potassium, so the precipitate is only $2-3 \mathrm{x}$ lower in Cs-137.

This equivalent amount of slurry can be used to calculate the benzene release expected in full-scale operations (based on the Tank 48 data):

Benzene release $\left.(\mathrm{ppm})=(2.7 \mathrm{ppm}) \times \frac{(1,05.0 .000 \mathrm{gal}}{14.400 \mathrm{gal}} \times \frac{(36 \mathrm{ci} / \mathrm{gal}}{15 \mathrm{ci} / \mathrm{gal}}\right)$

$=470 \mathrm{ppm}$ (at ventilation flowrate $=330 \mathrm{cfm}$ )

The corresponding release for a full year is:

$$
\begin{aligned}
& \text { Benzene release (tons) } \left.=\frac{\left(\frac{0.472 \mathrm{~mL}}{1000 \mathrm{~mL}}\right)}{22.4 \mathrm{~L}} \frac{(1 \mathrm{~mole}}{22} \times \frac{\left(330 \mathrm{ft}^{3}\right.}{\mathrm{min}}\right) \times \frac{(\mathrm{l} .0781 \mathrm{~kg})}{\text { mole }}
\end{aligned}
$$

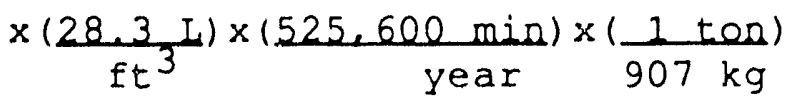

$$
\begin{aligned}
& =8.9 \text { tons/year }( \pm 3.1 \text { tons })
\end{aligned}
$$

The error in this number is the same as the error in the G-value $( \pm 35 \%)$. 
TABLE C

Sodium Tetraphenylborate Material Balance

for the Full Scale In-Tank Demonstration

\begin{tabular}{lll} 
Volume & NATPB & NATPB \\
(gal) & (melar) & $\begin{array}{l}\text { Amount } \\
\text { (libs) }\end{array}$ \\
\hline
\end{tabular}

I. NaTPB into Tank 48
a) Cold Chemical Run-in
3,200
Tests
b) Full-scale Test
Total in
32,800
36,000

II. NaTPB removed from Tank 48
a) Cold Chemical Filtrate (to Tank 49)
b) Decontaminated salt Solution (to Tank 50)
c) First Wash Filtrate (to Tank 49)
d) Second wash Filtrate (to Tank 49)
e) Third Wash Filtrate (to Tank 49) Total

$\begin{array}{rl}47,000 & .014 \text { (est) } \\ 518,000 & .0016 \\ 78,000 & .067 \\ 88,000 & .025 \\ 7,000 & .0088\end{array}$

$$
\begin{array}{r}
1,900 \\
2,400 \\
14,900 \\
6,300 \\
200 \\
\hline
\end{array}
$$

III. NaTPB left in Tank 48
a) Cold Chemical
Precipitate
$\left(300 \# \mathrm{KNO}_{3}\right.$ )

b) Potassium in Tank 24

Salt Solution
c) Solution Remaining in
Tank 48
Total

$427,000 \quad .007$

8,500

1,000

Total accounted for (sum of II and III):

1,300

10,800

36,500 


\section{Appendix D \\ Calculation of Decomposition of KTPB}

It is possible to calculate the extent of the decomposition of KTPB expected in two years of tank farm storage using the

$G$ (-KTPB)-values iisted in Table II. This calculation requires the assumption that the loss of KTPB is not dependent on wt \& KTPB but only on the amount of energy deposited in the sample. Evidence supporting this was given in Reference 2 .

The of decomposition per year is given by:

$\%$ Decomposition $=$ moles of $\mathrm{KTPB}$ lest (per $\mathrm{mL}$ ) moles of KTPB initially (per $\mathrm{mL}$ )

$$
\begin{aligned}
& =\left(\frac{(2.13 \text { melecules }) \times\left(1.45 \times 10^{8}\right.}{100 \mathrm{eV}} \text { years }\right) \times\left(\frac{1 \text { mole }}{6.02 \times 10^{23} \text { molecules }}\right) \\
& \times\left(6.24 \times 10^{13} \mathrm{eV} / \mathrm{g}\right) \times(1 \mathrm{~g}) \times(1 \mathrm{~mL} \text { of slurry }) \times 100 \\
& 1 \mathrm{rad} \mathrm{mL} 0.000267 \text { moles TPB- } \\
& =7.3 \pm 1.18 \text { (per year) }
\end{aligned}
$$

The number of moles of tetraphenylborate per $\mathrm{mL}$ of 10 wt 8 slurry is obtained by adding together the cesium, potassium, and ammonium TPB given in the CPES material balance (Ref. 8). The estimate of the error is based on the error in the G-value.

A similar calculation can be made for the decomposition occuring in Tank 48. If one assumes that the rates of decomposition of potassium and cesium salts are equal, then the rate of accumulation of cesium in the Tank 48 supernate is equal to the decomposition rate. The calculation is:

? Decomposition $=$ change in soluble $\mathrm{Cs}-137$ curies total Cs-137 curies

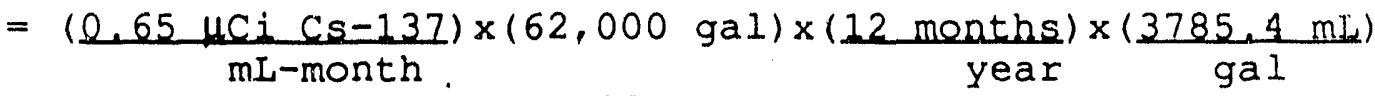

$$
\begin{aligned}
& x\left(\frac{1}{2.2 \times 10^{5} \text { Curies }}\right) \times 100
\end{aligned}
$$

$=0.838$ (per year) for current Tank 48 slurry.

This may be corrected for the low cesium-137 concentration in Tank 48 and then compared to the decomposition rate expected in Tank 48 under full scale operations with "average" slurry:

\& Decomposition $=0.83 \%\left(\frac{36 \mathrm{Ci} / \mathrm{gal}}{15}\right)$

$$
=2.0 \% \text { (per year) for "average" slurry. }
$$



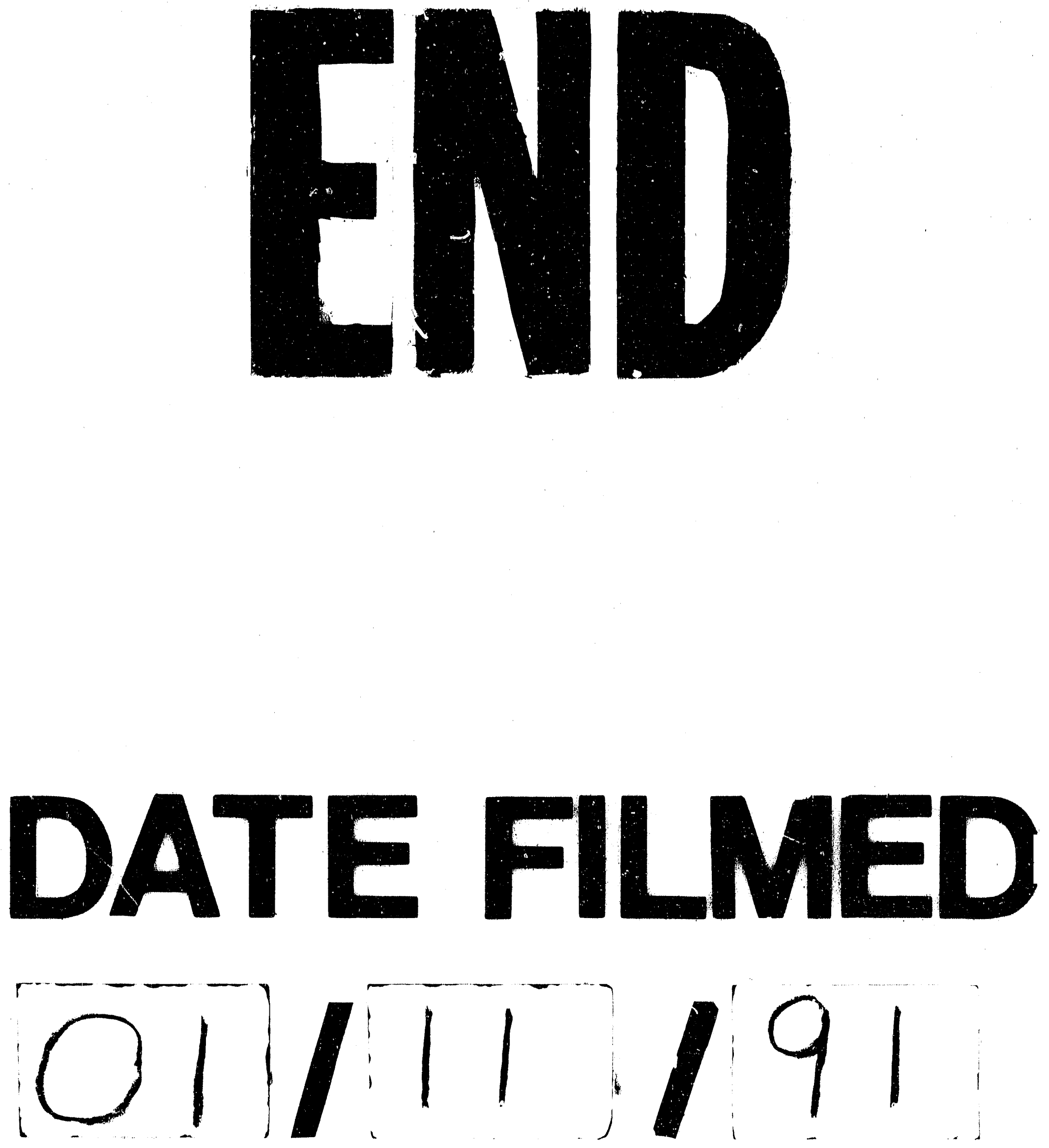
